\title{
The cyclopropene radical cation: Rovibrational level structure at low energies from high-resolution photoelectron spectra
}

\section{Journal Article}

Author(s):

Vasilatou, Konstantina; Michaud, Jérémy M.; Baykusheva, Denitsa; Grassi, Guido; Merkt, Frédéric; Vasilatou, Konstantina; Michaud, Jérémy M.; Baykusheva, Denitsa; Grassi, Guido; Merkt, Frédéric

Publication date:

2014-08-14

Permanent link:

https://doi.org/10.3929/ethz-a-010779040

Rights / license:

In Copyright - Non-Commercial Use Permitted

Originally published in:

The Journal of Chemical Physics 141(6), https://doi.org/10.1063/1.4890744

Funding acknowledgement:

146759 - Rydberg states, VUV laser spectroscopy and photoionization dynamics (SNF) 
This article may be downloaded for personal use only. Any other use requires prior permission of the author and AIP Publishing.

The following article appeared in J. Chem. Phys. 141, 064317 (2014) and may be found at http://dx.doi.org/10.1063/1.4890744. 


\section{AIP | The Journal of Chemical Physics}

The cyclopropene radical cation: Rovibrational level structure at low energies from high-resolution photoelectron spectra

K. Vasilatou, J. M. Michaud, D. Baykusheva, G. Grassi, and F. Merkt

Citation: The Journal of Chemical Physics 141, 064317 (2014); doi: 10.1063/1.4890744

View online: http://dx.doi.org/10.1063/1.4890744

View Table of Contents: http://scitation.aip.org/content/aip/journal/jcp/141/6?ver=pdfcov

Published by the AIP Publishing

\section{Articles you may be interested in}

Effective potential energy curves of the ground electronic state of $\mathrm{CH}+$

J. Chem. Phys. 138, 024315 (2013); 10.1063/1.4774374

Torsional vibrational structure of the propene radical cation studied by high-resolution photoelectron spectroscopy

J. Chem. Phys. 135, 124310 (2011); 10.1063/1.3638182

Photoelectron spectroscopic study of the $\mathrm{E} \otimes \mathrm{e}$ Jahn-Teller effect in the presence of a tunable spin-orbit interaction. I. Photoionization dynamics of methyl iodide and rotational fine structure of $\mathrm{CH} 3 \mathrm{I}+$ and $\mathrm{CD} 3 \mathrm{I}+$ J. Chem. Phys. 134, 054308 (2011); 10.1063/1.3547548

High-resolution pulsed-field-ionization zero-kinetic-energy photoelectron spectroscopic study of the two lowest electronic states of the ozone cation $\mathrm{O} 3+$

J. Chem. Phys. 122, 024311 (2005); 10.1063/1.1829974

Ionization from a double bond: Rovibronic photoionization dynamics of ethylene, large amplitude torsional motion and vibronic coupling in the ground state of $\mathrm{C} 2 \mathrm{H} 4+$

J. Chem. Phys. 120, 1761 (2004); 10.1063/1.1635815

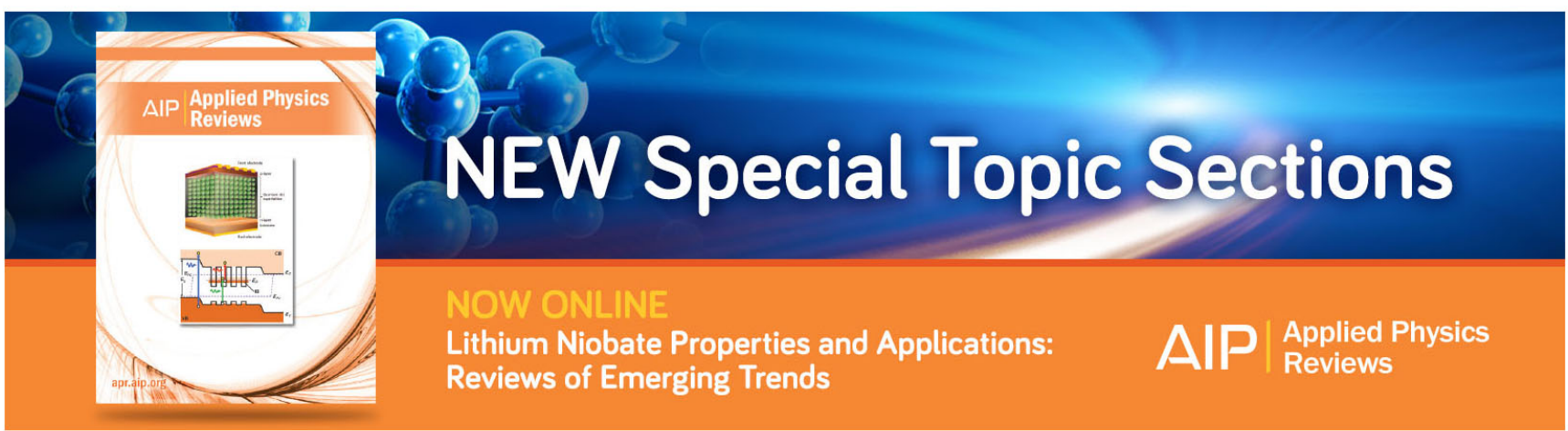




\title{
The cyclopropene radical cation: Rovibrational level structure at low energies from high-resolution photoelectron spectra
}

\author{
K. Vasilatou, J. M. Michaud, D. Baykusheva, G. Grassi, and F. Merkt \\ Laboratorium für Physikalische Chemie, ETH Zürich, CH-8093 Zurich, Switzerland
}

(Received 29 May 2014; accepted 8 July 2014; published online 14 August 2014)

\begin{abstract}
The cyclopropene radical cation $\left(c-\mathrm{C}_{3} \mathrm{H}_{4}^{+}\right)$is an important but poorly characterized three-memberedring hydrocarbon. We report on a measurement of the high-resolution photoelectron and photoionization spectra of cyclopropene and several deuterated isotopomers, from which we have determined the rovibrational energy level structure of the $\widetilde{\mathrm{X}}^{+}{ }^{2} \mathrm{~B}_{2}$ ground electronic state of $c-\mathrm{C}_{3} \mathrm{H}_{4}^{+}$at low energies for the first time. The synthesis of the partially deuterated isotopomers always resulted in mixtures of several isotopomers, differing in their number of D atoms and in the location of these atoms, so that the photoelectron spectra of deuterated samples are superpositions of the spectra of several isotopomers. The rotationally resolved spectra indicate a $C_{2 \mathrm{v}}$-symmetric $R_{0}$ structure for the ground electronic state of $c-\mathrm{C}_{3} \mathrm{H}_{4}^{+}$. Two vibrational modes of $c-\mathrm{C}_{3} \mathrm{H}_{4}^{+}$are found to have vibrational wave numbers below $300 \mathrm{~cm}^{-1}$, which is surprising for such a small cyclic hydrocarbon. The analysis of the isotopic shifts of the vibrational levels enabled the assignment of the lowest-frequency mode (fundamental wave number of $\approx 110 \mathrm{~cm}^{-1}$ in $\left.c-\mathrm{C}_{3} \mathrm{H}_{4}^{+}\right)$to the $\mathrm{CH}_{2}$ torsional mode $\left(v_{8}^{+}, \mathrm{A}_{2}\right.$ symmetry) and of the second-lowest-frequency mode $\left(\approx 210 \mathrm{~cm}^{-1}\right.$ in $\left.c-\mathrm{C}_{3} \mathrm{H}_{4}^{+}\right)$to a mode combining a $\mathrm{CH}$ out-of-plane with a $\mathrm{CH}_{2}$ rocking motion $\left(v_{15}^{+}, \mathrm{B}_{2}\right.$ symmetry). The potential energy along the $\mathrm{CH}_{2}$ torsional coordinate is flat near the equilibrium structure and leads to a pronounced anharmonicity. (C) 2014 AIP Publishing LLC. [http://dx.doi.org/10.1063/1.4890744]
\end{abstract}

\section{INTRODUCTION}

The physical and chemical properties of threemembered-ring molecules have been the object of extensive research. ${ }^{1-4}$ Especially cyclopropene (see Fig. 1), with many atypical structural parameters ${ }^{5-7}$ and a strain energy exceeding $50 \mathrm{kcal} / \mathrm{mol},{ }^{8,9}$ represents an extreme case of chemical bonding.

The existence and structure of $c-\mathrm{C}_{3} \mathrm{H}_{4}$ was first established by Dunitz et al. using the electron diffraction method..$^{5}$ A larger set of structural parameters was derived later by Kasai et al., ${ }^{6}$ who measured the microwave spectra of cyclopropene and three of its deuterated isotopomers, $c$ $\mathrm{CH}_{2} \mathrm{CDCH}, c-\mathrm{CH}_{2}(\mathrm{CD})_{2}$, and $c-\mathrm{CDH}(\mathrm{CH})_{2}$ and determined their rotational constants. The microwave spectrum of cyclopropene was further investigated by Stigliani $e t ~ a l .{ }^{7}$ who also studied the ${ }^{13} \mathrm{C}_{1}$ and ${ }^{13} \mathrm{C}_{2}$ isotopomers and were thus able to complete the structural determination of cyclopropene. Because three-membered-ring hydrocarbon molecules are of astrophysical interest, ${ }^{10}$ the investigations were extended to the millimeter-wave and submillimeter-wave regions of the spectrum. ${ }^{11,12}$ The analysis of these data combined with the previous microwave spectroscopic data yielded a more accurate set of rotational and centrifugal distortion constants, which was used to predict the positions of spectral lines over the entire radio-frequency range that could help in the detection of cyclopropene in the interstellar space.

The identification of a cyclopropene ring in two naturally occurring fatty acids, malvalic and sterculic acids (see Ref. 13 and references therein), and the interpretation of the IR spectra of these disubstituted cyclopropenes stimulated investigations of the IR spectra of $c-\mathrm{C}_{3} \mathrm{H}_{4}$. Part of the infrared spectrum of cyclopropene was reported in Ref. 14 in the context of a broader discussion of the structure and the spectra (IR, UV, and NMR) of a series of saturated and unsaturated cyclic compounds. More detailed studies of the vibrational spectrum of cyclopropene were then reported by Eggers et al. ${ }^{15}$ and by Mitchell et al. ${ }^{16}$ who also prepared and investigated partially deuterated samples. However, the rather low isotopic purity rendered the interpretation of the spectra difficult. The vibrational spectrum of cyclopropene was reinvestigated by Yum et al., ${ }^{17}$ who synthesized six deuterated isotopomers of cyclopropene and studied their infrared spectra at a resolution sufficiently high to enable a reliable analysis of the vibrational structure of all six isotopomers.

In contrast to the neutral species, the information currently available on the cyclopropene radical cation is limited to the partially resolved vibrational structure of $\mathrm{He} \mathrm{I}$ and $\mathrm{He}$ II photoelectron spectra. ${ }^{18-21}$ The first photoelectron band of cyclopropene arises from the ejection of an electron out of the highest occupied molecular orbital $\left(2 b_{2}\right)$ of cyclopropene, which has predominantly $\pi_{\mathrm{C}=\mathrm{C}}$ character. Its partially resolved vibrational structure revealed a vibrational interval of $\sim 1300 \mathrm{~cm}^{-1}$, indicative of a $\mathrm{C}-\mathrm{C}$ stretching mode. However, the observed anharmonicity raised questions concerning this assignment and the role of the methylene-centered $1 b_{2} \pi$ orbital in the three-membered rings. ${ }^{19}$ A significant mixing of the $\pi_{\mathrm{C}=\mathrm{C}}$ and the $1 \mathrm{~b}_{2} \pi$ molecular orbital would indeed imply a $\pi$-electron delocalization over the entire ring and result in a significant excitation of the scissoring mode of the methylenic hydrogens $\left(v_{5}\right)$ upon ionization.

Whereas the equilibrium geometry of neutral cyclopropene in its ground electronic state is of $C_{2 \mathrm{v}}$ symmetry, ${ }^{11}$ high-level ab initio calculations performed by Horný et al. for the cyclopropene radical cation in the $\widetilde{\mathrm{X}}^{+}$state with 


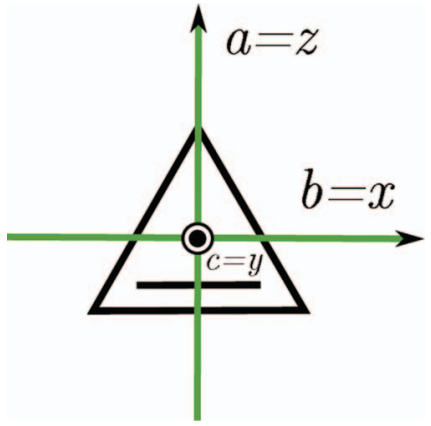

FIG. 1. Cyclopropene and its principal inertial axes in the $\mathrm{I}^{\mathrm{r}}$ convention for near-prolate asymmetric-top molecules.

extrapolation to a complete basis-set limit predict that the Born-Oppenheimer potential-energy surface along the $\mathrm{CH}_{2}$ torsional coordinate has two equivalent minima corresponding to $C_{2}$-symmetric structures. ${ }^{22}$ These two minima are separated by a potential-energy barrier with a maximum (saddle point) of about $470 \mathrm{~cm}^{-1}$ at the $C_{2 \mathrm{v}}$-symmetric position. The height of the potential barrier is predicted to increase to $\sim$ $690 \mathrm{~cm}^{-1}$ upon inclusion of zero-point-energy corrections. ${ }^{22}$ The equilibrium rotational constants of the $\widetilde{\mathrm{X}}^{+}$ground state of the cyclopropene radical cation and several deuterated isotopomers, and the fundamental vibrational wave numbers of the $C_{2}$-symmetric structure and the $C_{2 \mathrm{v}}$ transition state were also reported in Ref. 22.

The lack of high-resolution spectroscopic information on the energy-level structure of $c-\mathrm{C}_{3} \mathrm{H}_{4}^{+}$in the literature up to date reflects the experimental difficulties associated with spectroscopic measurements on molecular cations. Photoelectron spectroscopy enables studies of the energy-level structure of cations starting from the parent neutral molecules and circumvents the necessity to generate large densities of the cationic species. Moreover, photoionization selection rules provide access to a wide range of rovibronic levels of the cation. $^{23}$ Cyclopropene polymerizes at room temperature ${ }^{24}$ and is not commercially available. Moreover, it has not been possible so far to deuterate selectively specific sites of the molecule and previous studies of isotopically substituted cyclopropene had to be carried out using mixtures of several isotopomers. ${ }^{6,17}$ Given that photoelectron spectroscopy does not provide direct information on the mass of the investigated species, additional information must be acquired to identify the spectral structures of individual isotopomers. In the present case, the photoelectron spectroscopic data were complemented by photoionization mass-spectrometric data, which enabled us to assign most lines of the photoelectron spectra to specific isotopomers.

To determine the structure of the cyclopropene radical cation, we first determined the molecular-symmetry group from the rotational structure of the origin band of the $\widetilde{\mathrm{X}}^{+}$ $\leftarrow \widetilde{\mathrm{X}}$ photoionizing transition of cyclopropene utilizing general rovibronic photoionization selection rules. ${ }^{25}$ With the same selection rules, we then also determined the vibronic symmetry of the low-lying excited vibrational levels of $c-\mathrm{C}_{3} \mathrm{H}_{4}^{+}$from the rotational structure of the corresponding bands of the photoelectron spectrum. Finally, we characterized the vibrational modes by analyzing the isotopic shifts ob- served in the photoelectron spectra of $c-\mathrm{C}_{3} \mathrm{H}_{4}, c-\mathrm{CH}_{2} \mathrm{CHCD}$, $c-\mathrm{CH}_{2}(\mathrm{CD})_{2}, c-\mathrm{CD}_{2}(\mathrm{CH})_{2}, c-\mathrm{CHD}(\mathrm{CD})_{2}, c-\mathrm{CD}_{2} \mathrm{CHCD}$, and $c-\mathrm{C}_{3} \mathrm{D}_{4}$.

\section{EXPERIMENTAL}

\section{A. Synthesis of $c-\mathrm{C}_{3} \mathrm{H}_{4}$ and its deuterated isotopomers}

The synthesis of cyclopropene and its deuterated isotopomers (see Figs. 2-4) was performed by dropwise addition of the respective 3-chloroprop-1-ene (allyl chloride) isotopomer (1) into a boiling solution of sodium bis(trimethylsilyl)amide (NaHMDS) in toluene (Fig. 2). The synthesis was carried out as described by Binger et al. ${ }^{26-28}$ with only minor changes: the 3-chloroprop-1-ene isotopomers were added via an automatic syringe dispenser and the deuterated cyclopropene products were condensed in a trap cooled with liquid nitrogen and further transferred into a lecture bottle.

The reaction presented in Fig. 2 was performed with five different allyl chloride isotopomers as precursors, as indicated in Figs. 3 and 4: 1,1- $d_{2}$-3-chloroprop-1-ene (1a), 1,1,2$d_{3}$-3-chloroprop-1-ene (1b), 1,1,2,3,3- $d_{5}$-3-chloroprop-1-ene (1c), 2,3,3-d $d_{3}$-3-chloroprop-1-ene (1d) (with an admixture of $25 \%$ 3,3- $d_{2}$-3-chloroprop-1-ene $\left(\mathbf{1 d}^{\prime}\right)$ ), and 3-chloroprop-1ene (1). (1) was purchased (Acros) and used without further purification, whereas the deuterated species (1a-1d) were synthesized in two to three steps.

3- $d$-prop-2-yn-1-ol-OD (4) was prepared from prop-2yn-1-ol (3) by three exchanging steps in $\mathrm{NaOD} / \mathrm{D}_{2} \mathrm{O}$ according to Korth et al. $^{29}$ In a second step, 3,3- $d_{2}$-prop-2-en-1-olOD (7a) and 2,3,3- $d_{3}$-prop-2-en-1-ol-OD (7b) were prepared by reduction of $\mathbf{4}$ with lithium aluminum hydride and lithium aluminum deuteride, respectively, with subsequent hydrolysis with deuterium oxide according to Stewart et al. ${ }^{30}$

For the synthesis of 1,1,2,3,3- $d_{5}$-prop-2-en-1-ol-OD (7c), however, a different synthetic route was followed. Prop-2ynoic acid methyl ester (5) was deuterated in a mixture of dichloromethane and a solution of potassium carbonate in deuterium oxide by phase-transfer catalysis with tetrabutylammonium iodide to give 3- $d$-prop-2-ynoic acid methyl ester (6) according to Svenda and Myers. ${ }^{31}$ In a second step, 7c was prepared by reduction of $\mathbf{6}$ with lithium aluminum deuteride and subsequent hydrolysis with deuterium oxide according to Orfanopoulos et al. $^{32}$

Prop-2-ynoic acid methyl ester (5) was also reduced with lithium aluminum deuteride in tetrahydrofuran and subsequent hydrolysis with water ${ }^{33}$ to get a mixture of
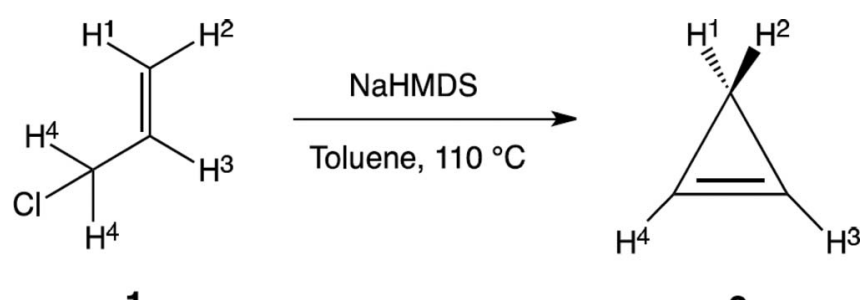

1

FIG. 2. Synthesis of cyclopropene 


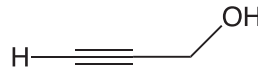

3

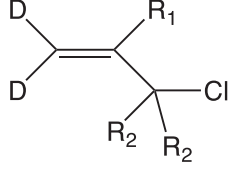

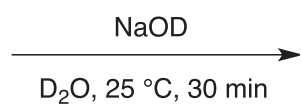

$\mathrm{D}_{2} \mathrm{O}, 25^{\circ} \mathrm{C}, 30 \mathrm{~min}$

$\mathrm{Ph}_{3} \mathrm{P}, \mathrm{Cl}_{3} \mathrm{CCOOEt}$, Sulfolane

$10^{\circ} \mathrm{C} ; 2 \mathrm{~h}, 25^{\circ} \mathrm{C}$

(a) $1 \mathrm{a}, \mathrm{R}_{1}=\mathrm{H}, \mathrm{R}_{2}=\mathrm{H}$

(b) $\mathbf{1 b}, \mathrm{R}_{1}=\mathrm{D}, \mathrm{R}_{2}=\mathrm{H}$

(c) $1 c, R_{1}=D, R_{2}=D$

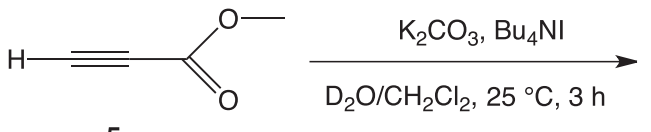

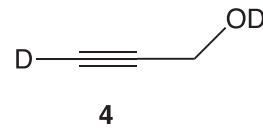

i) (a) $\mathrm{LiAlH}_{4}, \mathrm{Et}_{2} \mathrm{O}$ or

(b) $\mathrm{LiAlD}_{4}, \mathrm{Et}_{2} \mathrm{O}$

ii) $\mathrm{D}_{2} \mathrm{O}$

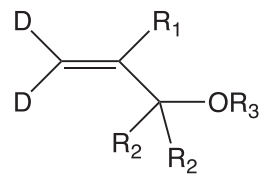

(a) $7 a, R_{1}=H, R_{2}=H, R_{3}=D$

(b) $7 b, R_{1}=D, R_{2}=H, R_{3}=D$

(c) $7 c, R_{1}=D, R_{2}=D, R_{3}=D$

FIG. 3. Synthesis of 1,1- $d_{2}$-3-chloroprop-1-ene (1a), 1,1,2- $d_{3}-3$-chloroprop-1-ene (1b), and 1,1,2,3,3- $d_{5}$-3-chloroprop-1-ene (1c).

$75 \%$ 1,1,2- $d_{3}$-prop-2-en-1-ol (7d) and 25\% 1,1- $d_{2}$-prop-2-en$1-\mathrm{ol}\left(\mathbf{7} \mathbf{d}^{\prime}\right)$.

In the last step, the chlorination of the deuterated prop-2-enols $\mathbf{7 a - 7 d}$ to the deuterated allyl chlorides 1a-1d, respectively, was performed by the reaction with 2,2,2-trichloroacetic acid ethyl ester in dioxothiolane (sulfolane) according to Matveeva et al. ${ }^{34}$ As $7 \mathbf{d}$ was synthesized with an admixture of $25 \% \mathbf{7} \mathbf{d}^{\prime}$, the chlorination (second step in the reaction scheme depicted in Fig. 4) also resulted in the formation of $25 \% \mathbf{1 d}$.

To our knowledge, the synthesis of the deuterated species with this method is presented here for the first time. Surprisingly, every attempt at deuterating a specific site of the cyclopropene molecule yielded a mixture of several different isotopomers. The composition of the different deuterated samples of cyclopropene depended on the choice of the deuterated allyl chloride used as precursor. Four substituted samples were used in our studies, the compositions
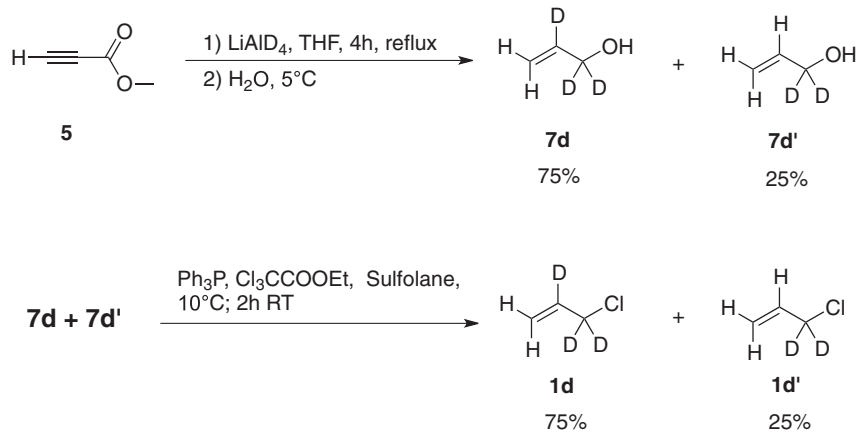

FIG. 4. Synthesis of 2,3,3- $d_{3}-3$-chloroprop-1-ene (1d) and 3,3-d $d_{2}-3-$ chloroprop-1-ene $\left(\mathbf{1 d}^{\prime}\right)$. of which are summarized in Table I. The percentage of each isotopomer in the mixtures was determined by VUV photoionization mass spectrometry.

As illustration, the time-of-flight spectrum of Sample 2 (see Table I) recorded following photoionization at a wave number of $78220 \mathrm{~cm}^{-1}$ is presented in Fig. 5. Five equally spaced peaks are observed in the spectrum indicating that the sample contains isotopomers of cyclopropene with all possible degrees of deuteration. The first peak in the spectrum at $\sim 5.12 \mu$ s corresponds to the time of flight of undeuterated cyclopropene cations and the last one at $\sim 5.37 \mu$ s to the time of flight of the perdeuterated species. The good mass resolution enabled the simultaneous recording of the photoionization spectra of different isotopomers in separate mass channels (see Fig. 10 and discussion in Subsection IV C).

\section{B. Photoionization and pulsed-field-ionization zero-kinetic-energy photoelectron spectra}

To record the photoelectron spectra of the $\widetilde{\mathrm{X}}^{+} \leftarrow \widetilde{\mathrm{X}}$ photoionizing transition of cyclopropene and its deuterated isotopomers we used a pulsed, tunable vacuum-ultraviolet (VUV) laser system in combination with a pulsed-fieldionization zero-kinetic-energy (PFI-ZEKE) photoelectron spectrometer. The spectra were obtained by monitoring the field ionization of high Rydberg states (principal quantum number $n \geq 200$ ) located immediately below the successive ionization thresholds ${ }^{35}$ as a function of the VUV wave number. The VUV radiation was generated from the outputs of two tunable Nd:YAG pulsed dye lasers by resonance-enhanced two-color difference-frequency mixing $\left(\widetilde{v}_{\mathrm{VUV}}=2 \widetilde{v}_{1}-\widetilde{v}_{2}\right)$ in a krypton cell using the $(4 p)^{5}\left({ }^{2} \mathrm{P}_{3 / 2}\right)$ 
TABLE I. Approximate composition (\%) of the deuterated samples determined by photoionization mass spectrometry.

\begin{tabular}{lcccccc}
\hline \hline Sample & Precursor & $c-\mathrm{C}_{3} \mathrm{H}_{4}$ & $c$-CHD $(\mathrm{CH})_{2}$ & $c-\mathrm{CD}_{2}(\mathrm{CH})_{2}$ & $c-\mathrm{CD}_{2} \mathrm{CDCH}$ & $c-\mathrm{C}_{3} \mathrm{D}_{4}$ \\
\hline 1 & $1 \mathrm{c}$ & 7 & 3 & 20 & 39 & 31 \\
2 & $1 \mathrm{~b}$ & 1 & 3 & 53 & 35 & 8 \\
3 & $1 \mathrm{a}$ & 2 & 15 & 77 & 6 & $\ldots{ }^{\mathrm{a}}$ \\
Sample & Precursor & $c-\mathrm{C}_{3} \mathrm{H}_{4}$ & $c-\mathrm{CH}_{2} \mathrm{CHCD}$ & $c-\mathrm{CH}_{2}(\mathrm{CD})_{2}$ & $c$-CHD $(\mathrm{CD})_{2}$ & $c$ - $\mathrm{C}_{3} \mathrm{D}_{4}$ \\
\hline 4 & $1 \mathrm{~d}+1 \mathrm{~d}^{\prime}$ & 15 & 40 & 40 & 5 & $\cdots$ \\
\hline \hline
\end{tabular}

${ }^{\mathrm{a}}$ Cannot be determined from the photoionization mass spectra. See discussion in Subsection IV B.

$5 p[1 / 2](J=0) \leftarrow(4 p)^{6}\left({ }^{1} \mathrm{~S}_{0}\right)$ two-photon resonance in krypton at $2 \widetilde{v}_{1}=94092.96 \mathrm{~cm}^{-1}$, as described in Ref. 36. The VUV wave number was scanned by tuning the wave number $\widetilde{v}_{2}$ of the second dye laser, which was calibrated by recording the laser-induced fluorescence spectrum of $\mathrm{I}_{2}$ simultaneously to the photoelectron spectra, as described in Refs. 37 and 38.

Survey PFI-ZEKE photoelectron spectra were recorded using the frequency-tripled output of a commercial dye laser to generate radiation at the wave number $\widetilde{v}_{1}$ needed for the krypton two-photon resonance and the fundamental output (wave number $\widetilde{v}_{2}$ ) of a second commercial dye laser. A twopulse electric-field sequence consisting of a $+85 \mathrm{mV} / \mathrm{cm}$ discrimination pulse and a $-850 \mathrm{mV} / \mathrm{cm}$ extraction pulse was employed for the field ionization, resulting in a resolution of about $0.5 \mathrm{~cm}^{-1}$. A correction of $+2.0(5) \mathrm{cm}^{-1}$ was introduced to compensate for the field-induced shift of the ionization thresholds.

The same laser system was also used to record photoionization spectra by monitoring the ion yield as a function of the VUV wave number. In this case, a positive electric-field pulse of typically $138 \mathrm{~V} / \mathrm{cm}$ was applied $1 \mu$ s after photoionization in order to extract the ions and accelerate them toward a microchannel-plate detector. Our time-of-flight mass spectrometer enabled us to separate species having a different degree of deuteration, but not species having the same

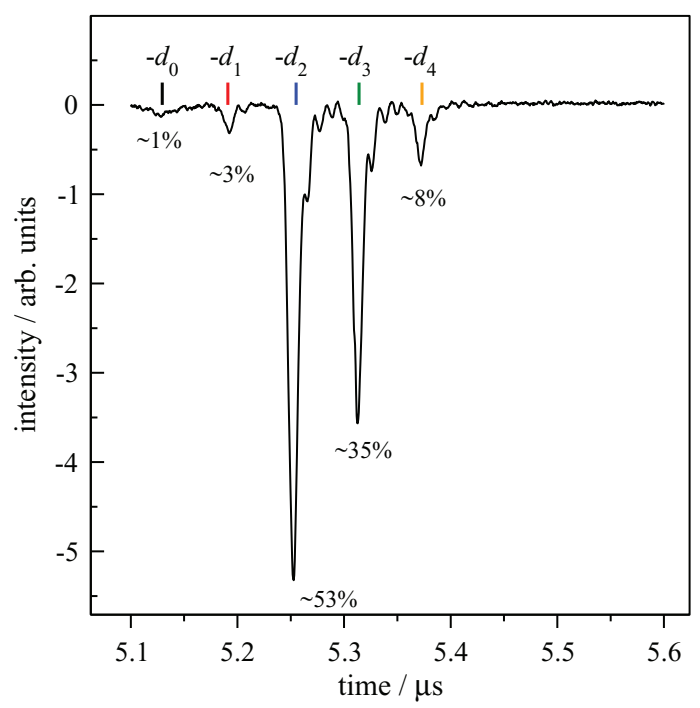

FIG. 5. Time-of-flight mass spectrum of Sample 2 (see Table I) recorded following ionization at a wave number of $78220 \mathrm{~cm}^{-1}$. number of deuterium atoms, but differing in the location of these atoms (see Fig. 5).

To record high-resolution photoelectron spectra, we used a tunable VUV laser with a Fourier-transform-limited bandwidth of better than $0.01 \mathrm{~cm}^{-1}$ (Ref. 37) in combination with a multipulse electric-field ionization sequence, ${ }^{38}$ delayed by $2.3 \mu$ s relative to the time of photoexcitation. An electric-field pulse sequence consisting of a positive discrimination pulse of $+167 \mathrm{mV} / \mathrm{cm}$ followed by negative extraction pulses of $-83 \mathrm{mV} / \mathrm{cm},-100 \mathrm{mV} / \mathrm{cm},-117 \mathrm{mV} / \mathrm{cm},-133 \mathrm{mV} / \mathrm{cm}$, $-150 \mathrm{mV} / \mathrm{cm},-167 \mathrm{mV} / \mathrm{cm},-183 \mathrm{mV} / \mathrm{cm},-200 \mathrm{mV} / \mathrm{cm}$, $-217 \mathrm{mV} / \mathrm{cm},-250 \mathrm{mV} / \mathrm{cm}$, and $-333 \mathrm{mV} / \mathrm{cm}$ enabled us to record PFI-ZEKE photoelectron spectra with a resolution of about $0.15 \mathrm{~cm}^{-1}$.

Mixtures of about $15 \%$ cyclopropene- $d_{0}$ or deuterated cyclopropenes in $\mathrm{Ar}$ at a total stagnation pressure of 2-4 bar were introduced into the chamber through a pulsed nozzle, forming a supersonic expansion. Polymerisation of cyclopropene at room temperature in the reservoir caused a gradual decrease of the signal with time, typically $30 \%$ during $6-8 \mathrm{~h}$ of measurement time. From the analysis of the rotationally resolved spectra, the rotational temperature of the sample in the supersonic beam was estimated to be in the range of 5-7 K.

\section{GROUP-THEORETICAL CONSIDERATIONS, SYMMETRY LABELS, AND ROVIBRONIC PHOTOIONIZATION SELECTION RULES}

The recent $a b$ initio calculations performed by Horný et al. for the cyclopropene radical cation in the $\widetilde{\mathrm{X}}^{+}$state predict a $C_{2}$ equilibrium structure, the plane containing the $\mathrm{CH}_{2}$ group being tilted away from that of the $C_{2 \mathrm{v}}$ structure of cyclopropene. ${ }^{22}$ Two equivalent $C_{2}$ structures arise along this methylenic torsional coordinate that are separated by a potential barrier having its maximum at the $C_{2 \mathrm{v}}$ point. When including the zero-point energy of the 14 remaining modes, the height of the barrier along the $\mathrm{CH}_{2}$ torsional coordinate is predicted to increase from $470 \mathrm{~cm}^{-1}$ to $690 \mathrm{~cm}^{-1}$. ${ }^{22}$ One therefore expects the ground state of $c-\mathrm{C}_{3} \mathrm{H}_{4}^{+}$to be split into two components by the tunneling effect.

When treating the rovibrational energy-level structure of $c-\mathrm{C}_{3} \mathrm{H}_{4}^{+}$group theoretically, two situations must be considered. If the tunneling splitting associated with the motion along the $\mathrm{CH}_{2}$ torsional coordinate cannot be resolved, the tunneling motion can be considered to be infeasible, ${ }^{39,40}$ and the appropriate molecular-symmetry group is $C_{2}(\mathrm{M}){ }^{41} \mathrm{In}$ this group, the $\mathrm{CH}_{2}$ torsional mode $\left(v_{8}^{+}\right)$is totally symmetric and transitions from the neutral ground state to torsional levels of 
the cation having even and odd numbers of vibrational quanta are allowed by the Franck-Condon principle. If the tunneling splitting is resolved, or if the lowest level of $c-\mathrm{C}_{3} \mathrm{H}_{4}^{+}$lies above the barrier, the $C_{2 \mathrm{v}}(\mathrm{M})$ group should be used. In this case, the torsional mode has $\mathrm{A}_{2}$ symmetry and only the torsional levels of the cation with an even number of quanta, i.e., levels with $v_{8}^{+}=0,2,4, \ldots$, are expected to be observable from the neutral ground state, which has $A_{1}$ vibrational symmetry.

The rovibronic photoionization symmetry selection rules were derived in the relevant molecular-symmetry groups using the equation ${ }^{25}$

$$
\Gamma_{\text {rve }}^{+} \otimes \Gamma_{\text {rve }}^{\prime \prime} \supseteq\left(\Gamma^{*}\right)^{\ell+1} .
$$

In this equation, $\Gamma_{\text {rve }}^{\prime \prime}\left(\Gamma_{\text {rve }}^{+}\right)$represents the irreducible representation of the rovibronic state of the neutral (cation), $\Gamma^{*}$ is the dipole-moment representation, and $\ell$ the orbital angular momentum quantum number of the outgoing photoelectron partial wave. A double prime and a plus sign are used to designate quantum numbers of the neutral and cationic states, respectively. The analysis of the rotational structure of cyclopropene was performed using a rigid-rotor Hamiltonian for near-prolate asymmetric tops. The choice of axes of the molecule-fixed coordinate system is presented in Fig. 1 and corresponds to the convention $\mathrm{I}^{\mathrm{r}}{ }^{42}$ The $z$ axis coincides with the twofold axis of symmetry, the $x$ axis is parallel to the carbon-carbon double bond, and the $y$ axis is perpendicular to the molecular plane.

The rovibronic photoionization symmetry selection rules can be expressed in terms of the changes $\Delta K_{a}=K_{a}^{+}-K_{a}^{\prime \prime}$ and $\Delta K_{c}=K_{c}^{+}-K_{c}^{\prime \prime}$ in the asymmetric-top quantum numbers $K_{a}^{\prime \prime}{ }^{(+)}$and $K_{c}{ }^{\prime \prime}{ }^{(+)}$of the neutral molecule (ion). ${ }^{25}$ Assuming that the equilibrium geometry of the cyclopropene radical cation is $C_{2 \mathrm{v}}$, Eq. (1) translates into

$$
\begin{gathered}
\Delta K_{a}=\text { odd }, \Delta K_{c}=\text { odd for } \ell=\text { odd }, \text { and } \\
\Delta K_{a}=\text { odd }, \Delta K_{c}=\text { even for } \ell=\text { even },
\end{gathered}
$$

for the $\widetilde{\mathrm{X}}^{+}\left(0^{0}, \Gamma_{\mathrm{ve}}^{+}=\mathrm{B}_{2}\right) \leftarrow \widetilde{\mathrm{X}}\left(0^{0}, \Gamma_{\mathrm{ve}}^{\prime \prime}=\mathrm{A}_{1}\right)$ ionizing transition of cyclopropene. Equivalently, the selection rules can be expressed in the notation $\Gamma_{\text {rve }}^{\prime \prime} \leftrightarrow \Gamma_{\text {rve }}^{+}$as

$$
\begin{gathered}
\mathrm{A}_{1} \leftrightarrow \mathrm{A}_{1} ; \mathrm{A}_{2} \leftrightarrow \mathrm{A}_{2} ; \mathrm{B}_{1} \leftrightarrow \mathrm{B}_{1} ; \mathrm{B}_{2} \leftrightarrow \mathrm{B}_{2} \text { for } \ell=\text { odd, and } \\
\mathrm{A}_{1} \leftrightarrow \mathrm{A}_{2} ; \mathrm{B}_{1} \leftrightarrow \mathrm{B}_{2} \text { for } \ell=\text { even. }
\end{gathered}
$$

If the molecular cation is treated in the $C_{2}(\mathrm{M})$ molecularsymmetry group, the selection rules can be easily deduced from Eqs. (3a) and ( $3 b$ ) by dropping the indices " 1 " and " 2 ":

$$
\mathrm{A} \leftrightarrow \mathrm{A} ; \mathrm{B} \leftrightarrow \mathrm{B},
$$

or equivalently

$$
\Delta K_{a}=\text { odd, } \Delta K_{c}=\text { even or odd }
$$

for both even- and odd- $\ell$ partial waves.

The analysis of the rotational structure observed in the photoelectron spectra of $c-\mathrm{CHD}(\mathrm{CH})_{2}$ and $c-\mathrm{CD}_{2} \mathrm{CHCD}$ must be performed in the $C_{\mathrm{s}}(\mathrm{M})$ molecular-symmetry group. In the first case, the plane of symmetry contains the $a$ and $c$ inertial axes and the symmetry of the ground electronic state of the cation is $\Gamma_{\mathrm{e}}^{+}=\mathrm{A}^{\prime}$. Using the convention $\mathrm{I}^{\mathrm{r}},{ }^{42}$ the selection rules

$$
\begin{aligned}
& \Delta K_{a}=\text { even/odd } \\
& \Delta K_{c}=\text { even/odd for both } \ell=\text { even and odd }
\end{aligned}
$$

result for the $\widetilde{\mathrm{X}}^{+}\left(0^{0}, \Gamma_{\mathrm{ve}}^{+}=\mathrm{A}^{\prime}\right) \leftarrow \widetilde{\mathrm{X}}\left(0^{0}, \Gamma_{\mathrm{ve}}^{\prime \prime}=\mathrm{A}^{\prime}\right)$ ionizing transition of $c-\mathrm{CHD}(\mathrm{CH})_{2}$.

In the case of $c-\mathrm{CD}_{2} \mathrm{CHCD}$, the symmetry plane is that defined by the $a$ and $b$ inertial axes and the symmetry of the ground electronic state of the cation is $\Gamma_{\mathrm{e}}^{+}=\mathrm{A}^{\prime \prime}$, and the photoionization selection rules for the $\widetilde{\mathrm{X}}^{+}\left(0^{0}, \Gamma_{\mathrm{ve}}^{+}=\mathrm{A}^{\prime \prime}\right)$ $\leftarrow \widetilde{\mathrm{X}}\left(0^{0}, \Gamma_{\mathrm{ve}}^{\prime \prime}=\mathrm{A}^{\prime}\right)$ ionizing transition are

$$
\begin{aligned}
\Delta K_{a} & =\text { even/odd } \\
\Delta K_{c} & =\text { odd for } \ell=\text { odd }, \text { and } \\
\Delta K_{a} & =\text { even/odd } \\
\Delta K_{c} & =\text { even for } \ell=\text { even. }
\end{aligned}
$$

To designate the vibrational modes, we use the convention described by Herzberg, ${ }^{43,44}$ with mode indices given in the order of the irreducible representations and, within each irreducible representation, in order of decreasing wave number. Using this convention, the same mode (e.g., the $\mathrm{CH}_{2}$ torsional mode) can have different mode indices in different isotopomers. Table II summarizes the mode indices for the low-frequency vibrations of the different isotopomers observed in this study. The mode associated with the $\mathrm{CH}_{2}$ torsion is $v_{8}^{+}$in the $C_{2 \mathrm{v}}(\mathrm{M})$ and $C_{2}(\mathrm{M})$ group, but $v_{15}^{+}$in the $C_{\mathrm{s}}(\mathrm{M})$ group.

\section{RESULTS}

\section{A. Rovibrational structure of the photoelectron spectrum of $c-\mathrm{C}_{3} \mathrm{H}_{4}$ and the molecular-symmetry group of $c-\mathrm{C}_{3} \mathrm{H}_{4}^{+}$}

The overview PFI-ZEKE photoelectron spectrum of the $\widetilde{\mathrm{X}}^{+} \leftarrow \widetilde{\mathrm{X}}$ transition of $c-\mathrm{C}_{3} \mathrm{H}_{4}$ in the vicinity of the adiabatic ionization threshold is presented in Fig. 6. Five bands are observed in the region up to $\sim 700 \mathrm{~cm}^{-1}$ of internal energy: the origin band at $\sim 77932 \mathrm{~cm}^{-1}$, a very weak band at $78043 \mathrm{~cm}^{-1}$, two relatively strong bands located $230 \mathrm{~cm}^{-1}$ and $414 \mathrm{~cm}^{-1}$ above the origin band, and a weak band at $78503 \mathrm{~cm}^{-1}$ (see Table III). Additional very weak bands are observed beyond $78400 \mathrm{~cm}^{-1}$.

The high-resolution PFI-ZEKE photoelectron spectrum of the origin band of the $\widetilde{\mathrm{X}}^{+} \leftarrow \widetilde{\mathrm{X}}$ transition of cyclopropene is displayed in Fig. 7(a). The sharpest lines in the experimental spectrum correspond to isolated transitions and have a full width at half maximum of $0.15 \mathrm{~cm}^{-1}$. These lines are labelled using the notation $N_{K_{a}^{\prime \prime} K_{c}^{\prime \prime}}^{\prime \prime} N_{K_{a}^{+} K_{c}^{+}}^{+}$.

The analysis of the rotational structure observed in the photoelectron spectrum of $c-\mathrm{C}_{3} \mathrm{H}_{4}$ was first performed in the $C_{2}(\mathrm{M})$ and $C_{2 \mathrm{v}}(\mathrm{M})$ groups using the photoionization selection rules (5), and (2a) and (2b), respectively. The rotational intensity distribution of the spectrum was calculated using the 
TABLE II. Correlation table of the symmetry species belonging to the $C_{2 \mathrm{v}}, C_{2}$, and $C_{\mathrm{s}}$ symmetry groups and numbering of the lowest-frequency vibrational modes of the isotopomers of the cyclopropene radical cation and of the neutral species.

\begin{tabular}{|c|c|c|c|c|c|}
\hline & & $C_{2 \mathrm{v}}{ }^{\mathrm{a}}$ & $C_{2}$ & $C_{\mathrm{s}}\left(\sigma_{y z}\right)^{\mathrm{b}}$ & $C_{\mathrm{s}}\left(\sigma_{x z}\right)^{\mathrm{c}}$ \\
\hline & & $\mathrm{A}_{1}$ & A & $\mathrm{A}^{\prime}$ & $\mathrm{A}^{\prime}$ \\
\hline & & $\mathrm{A}_{2}$ & A & $\mathrm{A}^{\prime \prime}$ & $\mathrm{A}^{\prime \prime}$ \\
\hline & & $\mathrm{B}_{1}$ & $\mathrm{~B}$ & $\mathrm{~A}^{\prime \prime}$ & $\mathrm{A}^{\prime}$ \\
\hline & & $\mathrm{B}_{2}$ & B & $\mathrm{A}^{\prime}$ & $\mathrm{A}^{\prime \prime}$ \\
\hline \multirow[t]{3}{*}{ Cationic species } & Methylenic torsion & $v_{8}^{+}\left(\Gamma_{\mathrm{v}}^{+}=\mathrm{A}_{2}\right)$ & $v_{8}^{+}\left(\Gamma_{\mathrm{v}}^{+}=\mathrm{A}\right)$ & $v_{15}^{+}\left(\Gamma_{\mathrm{v}}^{+}=\mathrm{A}^{\prime \prime}\right)$ & $v_{15}^{+}\left(\Gamma_{\mathrm{v}}^{+}=\mathrm{A}^{\prime \prime}\right)$ \\
\hline & $\mathrm{CH}$ (or CD) oop bend $\mathrm{d}^{\mathrm{d}}$ & $v_{14}^{+}\left(\Gamma_{\mathrm{v}}^{+}=\mathrm{B}_{2}\right)$ & $v_{14}^{+}\left(\Gamma_{\mathrm{v}}^{+}=\mathrm{B}\right)$ & $v_{8}^{+}\left(\Gamma_{\mathrm{v}}^{+}=\mathrm{A}^{\prime}\right)$ & $v_{13}^{+}\left(\Gamma_{\mathrm{v}}^{+}=\mathrm{A}^{\prime \prime}\right)$ \\
\hline & Methylenic rock ${ }^{\mathrm{e}}$ & $v_{15}^{+}\left(\Gamma_{\mathrm{v}}^{+}=\mathrm{B}_{2}\right)$ & $v_{15}^{+}\left(\Gamma_{\mathrm{v}}^{+}=\mathrm{B}\right)$ & $v_{9}^{+}\left(\Gamma_{\mathrm{v}}^{+}=\mathrm{A}^{\prime}\right)$ & $v_{14}^{+}\left(\Gamma_{\mathrm{v}}^{+}=\mathrm{A}^{\prime \prime}\right)$ \\
\hline Neutral & $\mathrm{CH}$ (or CD) oop bend $\mathrm{f}^{\mathrm{f}}$ & $v_{15}^{\prime \prime}\left(\Gamma_{\mathrm{v}}^{+}=\mathrm{B}_{2}\right)$ & $v_{15}^{\prime \prime}\left(\Gamma_{\mathrm{v}}^{+}=\mathrm{B}\right)$ & $v_{9}^{\prime \prime}\left(\Gamma_{\mathrm{v}}^{+}=\mathrm{A}^{\prime}\right)$ & $v_{15}^{\prime \prime}\left(\Gamma_{\mathrm{v}}^{+}=\mathrm{A}^{\prime \prime}\right)$ \\
\hline
\end{tabular}

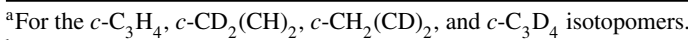

${ }^{\mathrm{b}}$ For the $c-\mathrm{CHD}(\mathrm{CH})_{2}$ and $c-\mathrm{CHD}(\mathrm{CD})_{2}$ isotopomers.

${ }^{\mathrm{c}}$ For the $c-\mathrm{CH}_{2} \mathrm{CHCD}$ and $c-\mathrm{CD}_{2} \mathrm{CDCH}$ isotopomers.

${ }^{\mathrm{d}}$ Contains also methylenic rocking motion.

${ }^{\mathrm{e}}$ Contains also $\mathrm{CH}$ (or $\mathrm{CD}$ ) oop bending motion.

${ }^{\mathrm{f}}$ See Ref. 46.

orbital ionization model described in detail in Ref. 45. In this model, the angular momentum of the photon is assumed to be fully absorbed by the outgoing photoelectron, creating a hole of the same angular-momentum composition as the molecular orbital out of which the electron is ejected. With the choice of axes presented in Fig. 1, the highest occupied molecular orbital of neutral cyclopropene is of $b$ and $b_{2}$ symmetry in the $C_{2}(\mathrm{M})$ and $C_{2 \mathrm{v}}(\mathrm{M})$ groups, respectively, and has one nodal plane, the plane defined by the three carbon atoms. This

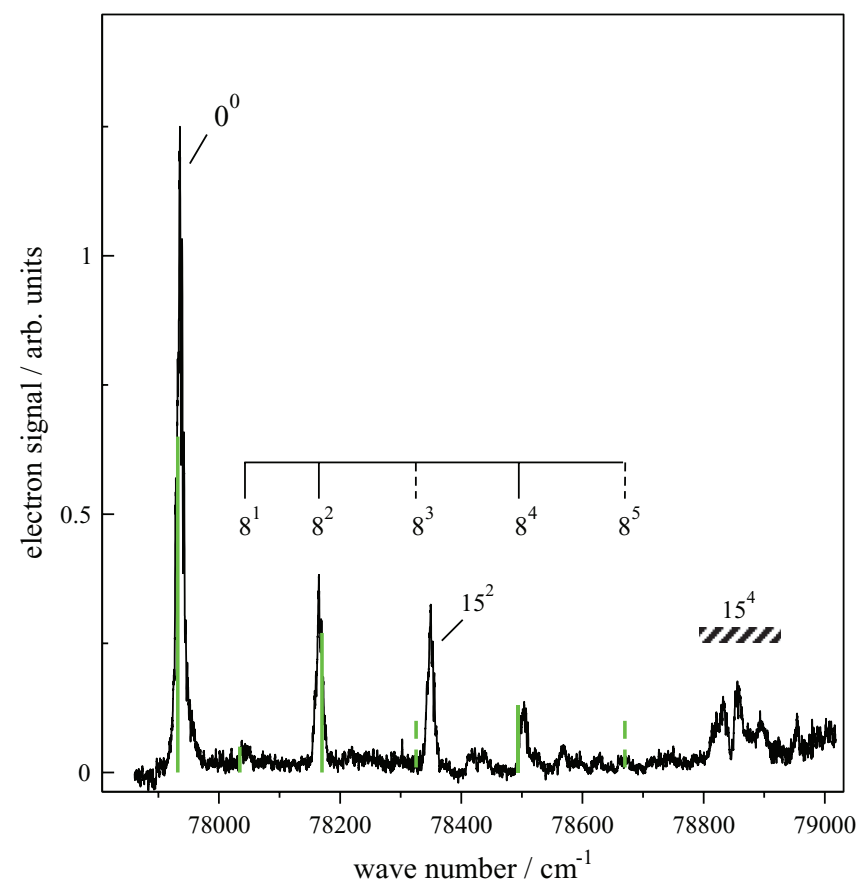

FIG. 6. Overview PFI-ZEKE photoelectron spectrum of the $\widetilde{\mathrm{X}}^{+} \leftarrow \widetilde{\mathrm{X}}$ ionizing transition of $c-\mathrm{C}_{3} \mathrm{H}_{4}$ at low energies. Two vibrational progressions have been identified and assigned to the $v_{8}^{+}\left(\mathrm{CH}_{2}\right.$ torsion) and $v_{15}^{+}$(mainly $\mathrm{CH}_{2}$ rocking) vibrational modes. The positions of the $\mathrm{CH}_{2}$ torsional levels are marked along the assignment bar. The dashed lines indicate the positions we expect for the levels that were not observed experimentally. The wave number region where the $15_{0}^{4}$ band is anticipated is denoted by a horizontal bar with diagonal stripes. molecular orbital can be described as a single-center expansion of atomic-like orbitals around the center of charge and its $b_{2}$ symmetry restricts the expansion to orbitals having a quantum number $\left|\lambda^{\prime \prime}\right|=1$ for the projection of the orbital angular momentum onto the principal axis $z=a$ (see Fig. 1). The dominant rotational branches are therefore expected to be those obeying the conditions $|\Delta N|=\left|N^{+}-N^{\prime \prime}\right| \leq 2$ and $\Delta K_{a}=K_{a}^{+}-K_{a}^{\prime \prime}=\lambda^{\prime \prime}= \pm 1$. The parameters that were optimized in the analysis of the spectrum included the adiabatic ionization energy, the rotational constants of $c-\mathrm{C}_{3} \mathrm{H}_{4}^{+}$, the rotational temperature of the sample, and the relative intensities of the different rotational branches. The rotational constants of the neutral ground state were kept fixed at the values reported in Ref. 6.

The rovibronic photoionization selections rule appropriate for the $C_{2}(\mathrm{M})$ group (Eq. (5)) are less restrictive than those appropriate for the $C_{2 \mathrm{v}}(\mathrm{M})$ group (Eqs. (2a) and (2b)) and lead to a higher density of lines than observed experimentally. Consequently, all attempts to reproduce the spectrum using the $C_{2}(\mathrm{M})$ group remained unsuccessful, and the analysis was performed using the $C_{2 \mathrm{v}}(\mathrm{M})$ group. The optimized molecular constants of the radical cation determined from the analysis of the rotational structure are presented in Table IV. The best agreement with the experimental spectrum was achieved for a rotational temperature of $\sim 5 \mathrm{~K}$ and by taking into account the angular-momentum components $\left(\ell^{\prime \prime}, \lambda^{\prime \prime}\right)=(1, \pm 1)$ and $(2$, \pm 1 ) with weights of 0.65 and 1.9, respectively. Cyclopropene has two pairs of identical protons, giving rise to nuclear-spin statistical factors of 6 or 10 depending on the even or odd nature of $K_{a}^{\prime \prime}$, respectively. The calculated spectrum is presented in Fig. 7(b) and reproduces the observed line positions and intensity distribution satisfactorily. The density of lines in the PFI-ZEKE photoelectron spectrum of the $0_{0}^{0}$ band is high and only a selected number of transitions are labelled in Fig. 7(a) for clarity. To nevertheless provide a complete assignment, the calculated spectrum shown in Fig. 7(b) was decomposed into groups of transitions corresponding to $\left(K_{a}^{\prime \prime}, K_{a}^{+}\right)$values of $(2,1),(1,0),(0,1)$, and $(1,2)$ (traces (c)-(f)) which exhibit branches for all possible values of $\Delta N(0-2)$ allowed by the orbital ionization model. 
TABLE III. Band positions (in $\left.\mathrm{cm}^{-1}\right)$, experimental $\left(\tilde{v}_{\text {obs. }}\right)$ vibrational wave numbers, and assignment of the low-lying vibrational levels of $c$ - $\mathrm{CH}_{2}(\mathrm{CH})_{2}^{+}$, $c-\mathrm{CH}_{2} \mathrm{CHCD}^{+}, c-\mathrm{CH}_{2}(\mathrm{CD})_{2}^{+}, c-\mathrm{CD}_{2}(\mathrm{CH})_{2}^{+}, c-\mathrm{CHD}(\mathrm{CD})_{2}^{+}, c-\mathrm{CD}_{2} \mathrm{CDCH}^{+}$, and $c-\mathrm{C}_{3} \mathrm{D}_{4}^{+}$.

\begin{tabular}{|c|c|c|c|c|c|c|c|c|}
\hline \multirow[b]{2}{*}{ Label $^{\mathrm{a}}$} & \multicolumn{2}{|c|}{$c-\mathrm{C}_{3} \mathrm{H}_{4}^{+}$} & \multicolumn{2}{|c|}{$c-\mathrm{CD}_{2}(\mathrm{CH})_{2}^{+}$} & \multicolumn{2}{|c|}{$c-\mathrm{CD}_{2} \mathrm{CDCH}^{+}$} & \multicolumn{2}{|c|}{$c-\mathrm{C}_{3} \mathrm{D}_{4}^{+}$} \\
\hline & $\tilde{v}_{\text {obs }}$ & $\left(\tilde{v}_{\mathrm{obs}}-\tilde{v}_{\mathrm{i}}\right)$ & $\tilde{v}_{\text {obs }}$ & $\left(\tilde{v}_{\mathrm{obs}}-\tilde{v}_{\mathrm{i}}\right)$ & $\tilde{v}_{\text {obs }}$ & $\left(\tilde{v}_{\mathrm{obs}}-\tilde{v}_{\mathrm{i}}\right)$ & $\tilde{v}_{\text {obs }}$ & $\left(\tilde{v}_{\mathrm{obs}}-\tilde{v}_{\mathrm{i}}\right)$ \\
\hline $14^{+}(1) \leftarrow 15^{\prime \prime}(1)^{\mathrm{b}}$ & $\ldots$ & & $78041(5)^{\mathrm{c}}$ & $-37(5)$ & $78041(5)^{\mathrm{c}}$ & $-43(5)$ & $78049(5)^{\mathrm{c}}$ & $-37(5)$ \\
\hline $0^{0}$ & $77931.8(7)^{\mathrm{d}}$ & $\ldots$ & $78078.3(10)^{d}$ & $\ldots$ & $78084.2(15)^{\mathrm{d}}$ & $\ldots$ & $78086.3(20)^{\mathrm{d}}$ & $\ldots$ \\
\hline $8_{0}^{1}\left(\mathrm{~A}_{2}\right)$ & $78043(5)^{\mathrm{c}}$ & $111(5)$ & $\ldots$ & $\ldots$ & $\ldots$ & $\ldots$ & $\ldots$ & $\ldots$ \\
\hline $8_{0}^{2}\left(\mathrm{~A}_{1}\right)$ & $78161.8(20)^{\mathrm{d}}$ & $230(2)$ & $78253(4)^{\mathrm{e}}$ & $175(4)$ & $78256(4)^{\mathrm{e}}$ & $171(4)$ & $78260(5)^{\mathrm{f}}$ & $174(5)$ \\
\hline $15_{0}^{2}\left(\mathrm{~A}_{1}\right)$ & $78345.6(20)^{\mathrm{d}}$ & $414(2)$ & $78381(4)^{\mathrm{c}}$ & $303(4)$ & $78362(4)^{\mathrm{c}}$ & $278(4)$ & $78344(4)^{c}$ & $258(4)$ \\
\hline $8_{0}^{4}\left(\mathrm{~A}_{1}\right)$ & $78503(4)^{\mathrm{c}}$ & $571(4)$ & $\cdots$ & $\cdots$ & $\cdots$ & $\ldots$ & $\cdots$ & $\ldots$ \\
\hline \multirow{2}{*}{$15_{0}^{4}\left(\mathrm{~A}_{1}\right)$} & $78812-78909^{f}$ & 880-977 & $\ldots$ & $\ldots$ & $\ldots$ & & $\ldots$ & $\ldots$ \\
\hline & \multicolumn{2}{|c|}{$c-\mathrm{CH}_{2} \mathrm{CHCD}^{+}$} & \multicolumn{2}{|c|}{$c-\mathrm{CH}_{2}(\mathrm{CD})_{2}^{+}$} & \multicolumn{2}{|c|}{${ }^{c}$ - $\mathrm{CHD}(\mathrm{CD})_{2}^{+}$} & & \\
\hline Label $^{\mathrm{a}}$ & $\tilde{v}_{\text {obs }}$ & $\left(\tilde{v}_{\mathrm{obs}}-\tilde{v}_{\mathrm{i}}\right)$ & $\tilde{v}_{\text {obs }}$ & $\left(\tilde{v}_{\mathrm{obs}}-\tilde{v}_{\mathrm{i}}\right)$ & $\tilde{v}_{\text {obs }}$ & $\left(\tilde{v}_{\mathrm{obs}}-\tilde{v}_{\mathrm{i}}\right)$ & & \\
\hline $0^{0}$ & $77927(4)^{\mathrm{e}}$ & $\ldots$ & $77932(4)^{\mathrm{e}}$ & $\ldots$ & $78013(4)^{\mathrm{c}}$ & $\ldots$ & & \\
\hline $8_{0}^{1}\left(\mathrm{~A}_{2}\right)$ & $78034(5)^{\mathrm{c}}$ & $107(6)$ & $78034(4)^{\mathrm{c}}$ & 102 & $\ldots$ & $\ldots$ & & \\
\hline $8_{0}^{2}\left(\mathrm{~A}_{1}\right)$ & $78160(5)^{\mathrm{c}}$ & $233(6)$ & $78160(5)^{\mathrm{c}}$ & $228(6)$ & $\sim 78218^{\mathrm{b}, \mathrm{c}}$ & $\sim 205$ & & \\
\hline
\end{tabular}

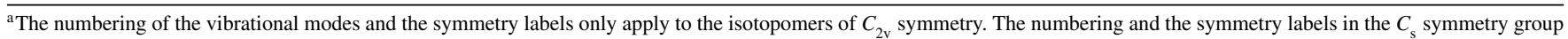
are presented in Table II.

${ }^{\mathrm{b}}$ Tentative assignment.

${ }^{\mathrm{c}}$ From survey PFI-ZEKE photoelectron spectra.

${ }^{\mathrm{d}}$ From high-resolution PFI-ZEKE photoelectron spectra.

${ }^{\mathrm{e}}$ From photoionization spectra.

${ }^{\mathrm{f}}$ Wave-number range where the $15_{0}^{4}$ band is expected to lie.

Because the next two most intense bands of the photoelectron spectrum of $c-\mathrm{C}_{3} \mathrm{H}_{4}$ (the third and fourth bands in Fig. 6) are about three to four times weaker than the origin band, a larger extraction electric field of $-330 \mathrm{mV} / \mathrm{cm}$ had to be applied to obtain PFI-ZEKE photoelectron spectra with a sufficient signal-to-noise ratio, which limited the resolution to about $0.5 \mathrm{~cm}^{-1}$. The partially rotationally resolved spectra of these bands are displayed in panels (a) and (b) of Fig. 8 (middle traces).

In these panels, the inverted traces correspond to the spectra calculated based on the assumption that the ionic state has $\mathrm{A}_{1}$ vibrational symmetry. The rotational constants and the intensity weighting factors of the different rotational branches were kept fixed at the values determined from the analysis of the origin band (see Fig. 7(a)). The only parameters that were varied were the ionization energies, the optimized values of which are listed in Table III. In both cases, the calculated spectra reproduce the partially resolved rotational structures on the high-energy side of the experimental spectra well, but overestimate the intensity of the cluster of overlapping lines located on the low-energy side. An explanation for this observation could be the gradual degradation of the sample during the measurements, which, for technical reasons, had to be performed by scanning the VUV radiation from high to low wave numbers. Calculations of the rotational structure assuming $A_{2}, B_{1}$, and $B_{2}$ vibrational symmetry for the cationic states led to spectra that do not correspond closely to the experimental observations, as is illustrated for the $A_{2}$ and $B_{2}$ vibrational symmetries on top of Figs. 8(a) and 8(b), respectively. This observation indicates that both vibrational levels must be either the fundamentals of totally symmetric or first overtones of nontotally symmetric vibrational modes.
All modes of $A_{1}$ vibrational symmetry of the cyclopropene radical cation have fundamental wave numbers larger than $600 \mathrm{~cm}^{-1}$ according to the $a b$ initio calculations presented in Ref. 22. Consequently, the observed vibrationally excited states must be overtones of nontotally symmetric vibrational modes, which, in turn, implies extremely low fundamental wave numbers.

To characterize these modes, we recorded spectra of isotopically substituted cyclopropene, and analyzed the isotopic shifts arising from the deuteration of specific sites. As explained in Subsection II A, it was not possible to synthesize isotopically pure samples and the photoelectron spectra of isotopically substituted cyclopropene consisted of contributions from several isotopomers. In order to assign the bands to specific isotopomers in cases where the rotational structure could not be resolved, complementary information had to be obtained from photoionization spectroscopic measurements (see Subsection IV C). The PFI-ZEKE photoelectron spectra obtained from Samples 1, 2, and 4 (see Table I) are discussed in Subsection IV D and confirm the existence of several low-lying vibrational levels of the cation.

\section{B. Rotational structure of the origin bands of the photoelectron spectra and adiabatic ionization energies of $c-\mathrm{CHD}(\mathrm{CH})_{2}, c-\mathrm{CD}_{2}(\mathrm{CH})_{2}, c-\mathrm{CD}_{2} \mathrm{CDCH}$, and $c-C_{3} D_{4}$}

The high-resolution photoelectron spectrum of the overlapping origin bands of the $\widetilde{\mathrm{X}}^{+} \leftarrow \widetilde{\mathrm{X}}$ ionizing transition of the deuterated Samples $2\left(c-\mathrm{CD}_{2}(\mathrm{CH})_{2}(53 \%), c-\mathrm{CD}_{2} \mathrm{CDCH}\right.$ $(35 \%)$, and $c-\mathrm{C}_{3} \mathrm{D}_{4}(8 \%)$, see Table I) and $3\left(c-\mathrm{CHD}(\mathrm{CH})_{2}\right.$ (15\%), $c-\mathrm{CD}_{2}(\mathrm{CH})_{2}(77 \%)$, and $\left.c-\mathrm{CD}_{2} \mathrm{CDCH}(6 \%)\right)$ are 


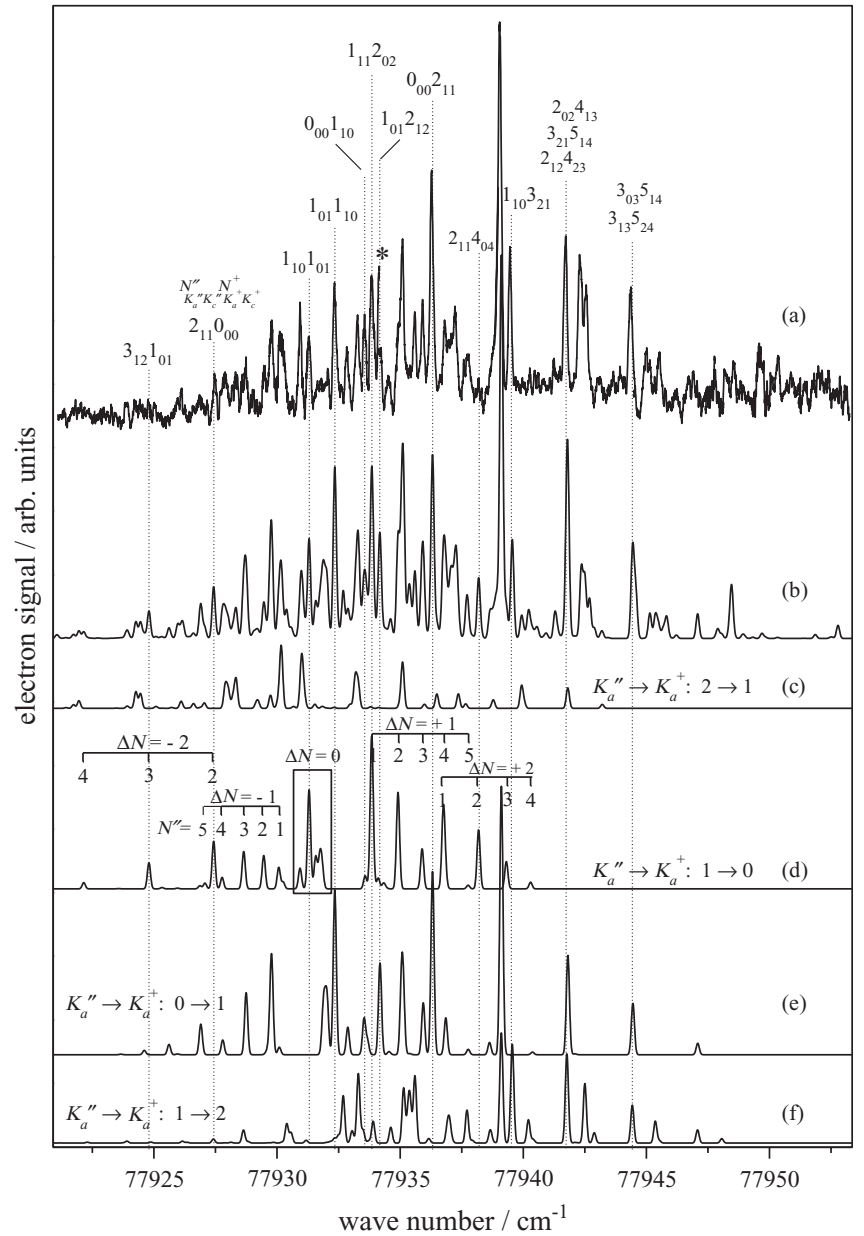

FIG. 7. Trace (a): High-resolution PFI-ZEKE photoelectron spectrum of the origin band of the $\widetilde{\mathrm{X}}^{+}{ }^{2} \mathrm{~B}_{2} \leftarrow \widetilde{\mathrm{X}}{ }^{1} \mathrm{~A}_{1}$ transition of $c-\mathrm{C}_{3} \mathrm{H}_{4}$. The asterisk placed at about $77934 \mathrm{~cm}^{-1}$ above trace (a) marks a discontinuity in the experimental spectrum caused by a mode hop of the tunable ring dye laser during the measurement. Trace (b): Calculated spectrum obtained by convolution of a stick spectrum (not shown) using a Gaussian function of full width at half maximum of $0.15 \mathrm{~cm}^{-1}$. Traces (c)-(f): Calculated contributions to the overall intensity distribution associated with rotational branches of specific values of $K_{a}^{\prime \prime}$ and $K_{a}^{+}$as indicated above each trace. displayed in the right and left panels of Fig. 9, respectively. Because the adiabatic ionization energy of $c-\mathrm{CHD}(\mathrm{CH})_{2}$ lies significantly lower in energy than those of $c-\mathrm{CD}_{2}(\mathrm{CH})_{2}$ and $c-\mathrm{CD}_{2} \mathrm{CDCH}$, and below the range depicted in Fig. 9, as will be discussed at the end of this subsection, the PFI-ZEKE photoelectron spectra shown in Fig. 9 have a dominant contribution from $c-\mathrm{CD}_{2}(\mathrm{CH})_{2}$ and weaker contributions from $c-\mathrm{CD}_{2} \mathrm{CDCH}$ and $c-\mathrm{C}_{3} \mathrm{D}_{4}$.

The partially resolved rotational structure observed in these PFI-ZEKE photoelectron spectra was analyzed using an iterative procedure. First, the contribution of $c-\mathrm{CD}_{2}(\mathrm{CH})_{2}$ to the spectrum obtained from Sample 3 (left panel of Fig. 9, Trace (a)) was calculated. The rotational constants of the neutral species were kept fixed to the values calculated $a b$ initio at the MP2/6-311G(2d,p) level (see Table IV) and the ionization energy and rotational constants of the cationic species were optimized. The rotational temperature of the sample was kept fixed at $7 \mathrm{~K}$. Once a satisfactory agreement between the observed and calculated spectra was reached, the calculated spectrum of $c-\mathrm{CD}_{2}(\mathrm{CH})_{2}^{+}$was subtracted from both experimental spectra, enabling us to analyze the rotational structure of the photoelectron spectrum of $c-\mathrm{CD}_{2} \mathrm{CDCH}$ and $c-\mathrm{C}_{3} \mathrm{D}_{4}$. The intensities of the transitions of $c-\mathrm{CD}_{2}(\mathrm{CH})_{2}$, which has one pair of identical protons and one pair of identical deuterons, were weighted by nuclear-spin statistical factors of 5 and 7 for even and odd values of $K_{a}^{\prime \prime}$, respectively. For $c-\mathrm{C}_{3} \mathrm{D}_{4}$, which has two pairs of identical deuterons, the intensities of the transitions were weighted by nuclear-spin statistical factors of 8 or 10 depending on the odd or even value of $K_{a}^{\prime \prime}$, respectively. Several iteration steps yielded the molecular constants listed in Table IV and to the decomposition of the overall spectra into contributions from selected isotopomers presented at the bottom of Fig. 9. The PFI-ZEKE photoelectron spectra calculated for the two mixtures (Trace (b) in each panel of Fig. 9) are in good agreement with the experimental spectra, which makes us confident that our procedure to decompose the spectra into contributions from the isotopomers constituting the mixtures and to determine the isotopic shifts is reliable.

TABLE IV. Molecular constants derived from the rotationally resolved PFI-ZEKE photoelectron spectra of cyclopropene and its deuterated isotopomers.

\begin{tabular}{|c|c|c|c|c|c|}
\hline & $\tilde{v}_{i}^{\mathrm{a}}\left(\mathrm{cm}^{-1}\right)$ & $A^{(+)}\left(\mathrm{cm}^{-1}\right)^{\mathrm{b}}$ & $B^{(+)}\left(\mathrm{cm}^{-1}\right)^{\mathrm{b}}$ & $C^{(+)}\left(\mathrm{cm}^{-1}\right)^{\mathrm{b}}$ & Refs. \\
\hline$c-\mathrm{C}_{3} \mathrm{H}_{4}$ & & 1.00281709 & 0.728023652 & 0.460175019 & 6 \\
\hline$c-\mathrm{C}_{3} \mathrm{H}_{4}^{+} 0^{0}$ & $77931.8(7)^{\mathrm{c}}$ & 0.960 & 0.774 & 0.459 & This work \\
\hline$c-\mathrm{CHD}(\mathrm{CH})_{2}$ & & 0.960484470 & 0.645663341 & 0.434020258 & 6 \\
\hline$c-\mathrm{CHD}(\mathrm{CH})_{2}^{+} 0^{0}$ & $78008.3(20)^{*}$ & $0.9494^{\dagger}$ & $0.6738^{\dagger}$ & $0.4303^{\dagger}$ & This work* ${ }^{*}$, Ref. $22^{\dagger}$ \\
\hline$c-\mathrm{CD}_{2}(\mathrm{CH})_{2}$ & & 0.911 & 0.581 & 0.413 & This work $^{\mathrm{d}}$ \\
\hline$c-\mathrm{CD}_{2}(\mathrm{CH})_{2}^{+} 0^{0}$ & $78078.3(10)$ & 0.872 & 0.619 & 0.413 & This work \\
\hline$c-\mathrm{CD}_{2} \mathrm{CHCD}$ & & 0.817 & 0.553 & 0.380 & This work $^{\mathrm{d}}$ \\
\hline$c-\mathrm{CD}_{2} \mathrm{CHCD}^{+} 0^{0}$ & $78084.2(15)$ & 0.781 & 0.589 & 0.379 & This work \\
\hline$c-\mathrm{C}_{3} \mathrm{D}_{4}$ & & 0.717 & 0.538 & 0.350 & This work $^{\mathrm{d}}$ \\
\hline$c-\mathrm{C}_{3} \mathrm{D}_{4}^{+} 0^{0}$ & $78086.3(20)$ & 0.685 & 0.573 & 0.350 & This work \\
\hline
\end{tabular}

${ }^{a}$ The values of the adiabatic ionization energy of the different isotopomers of cyclopropene have been corrected for the field-induced shift of the ionization energy.

${ }^{\mathrm{b}}$ The uncertainties in the values of the $A^{+}, B^{+}$, and $C^{+}$rotational constants are estimated to be $\pm 0.020 \mathrm{~cm}^{-1}, \pm 0.015 \mathrm{~cm}^{-1}$, and $\pm 0.010 \mathrm{~cm}^{-1}$, respectively.

${ }^{\mathrm{c}}$ The adiabatic ionization energy of $c-\mathrm{C}_{3} \mathrm{H}_{4}$ was determined to be $77994(240) \mathrm{cm}^{-1}$ from the He I photoelectron spectrum. ${ }^{19}$

${ }^{\mathrm{d} C a l c u l a t e d}$ ab initio at the MP2/6-311G(2d,p) level. 

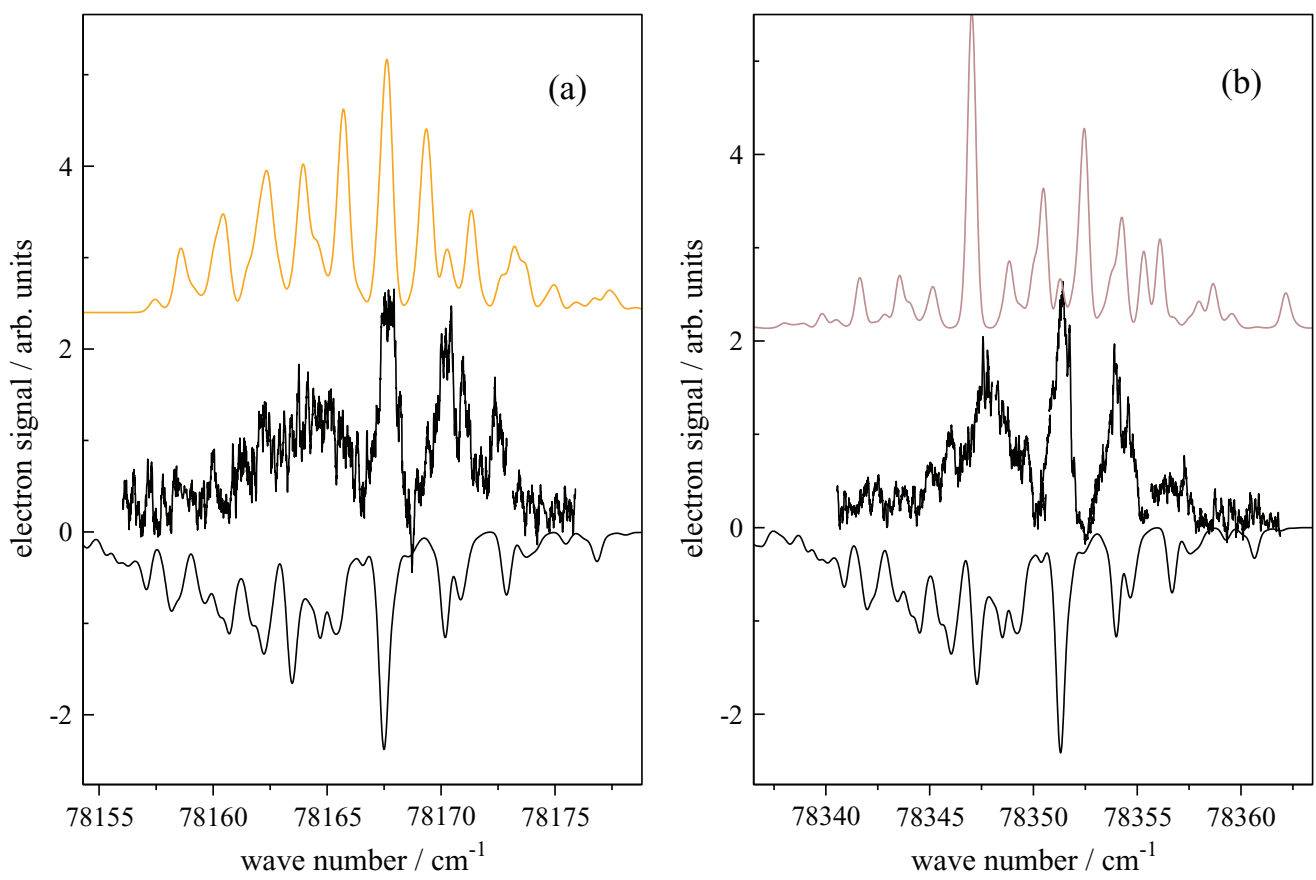

FIG. 8. High-resolution PFI-ZEKE photoelectron spectrum of the third (a) and fourth (b) bands of the $\widetilde{\mathrm{X}}^{+}{ }^{2} \mathrm{~B}_{2} \leftarrow \widetilde{\mathrm{X}}^{1} \mathrm{~A}_{1}$ ionizing transition of $c$ - $\mathrm{C}_{3} \mathrm{H}_{4}$ (middle trace). The discontinuities in the experimental spectra are caused by mode hops of the tunable ring dye laser during the measurement. The inverted traces correspond to the calculated spectra assuming that the vibrational state of the cation has $\Gamma_{\text {vib }}^{+}=\mathrm{A}_{1}$ symmetry. The calculated rotational contour of a band corresponding to cationic states of $\mathrm{A}_{2}$ and $\mathrm{B}_{2}$ vibrational symmetries are displayed at the top of panels (a) and (b), respectively, for comparison. The calculated spectra have been obtained by convoluting the stick spectra (not shown) with a Gaussian function with a full width at half maximum of $0.5 \mathrm{~cm}^{-1}$.

Whereas deuteration of the ethylenic sites of the molecule does not significantly shift the adiabatic ionization energy of cyclopropene, successive deuteration of the methylenic site lowers the adiabatic ionization energy in steps of about $75 \mathrm{~cm}^{-1}$. The PFI-ZEKE photoelectron spectrum of the origin band of $c$ - $\mathrm{CHD}(\mathrm{CH})_{2}$ is therefore located below the range depicted in Fig. 9. Because of the low concentration of this isotopomer in the mixture, a large extraction pulse
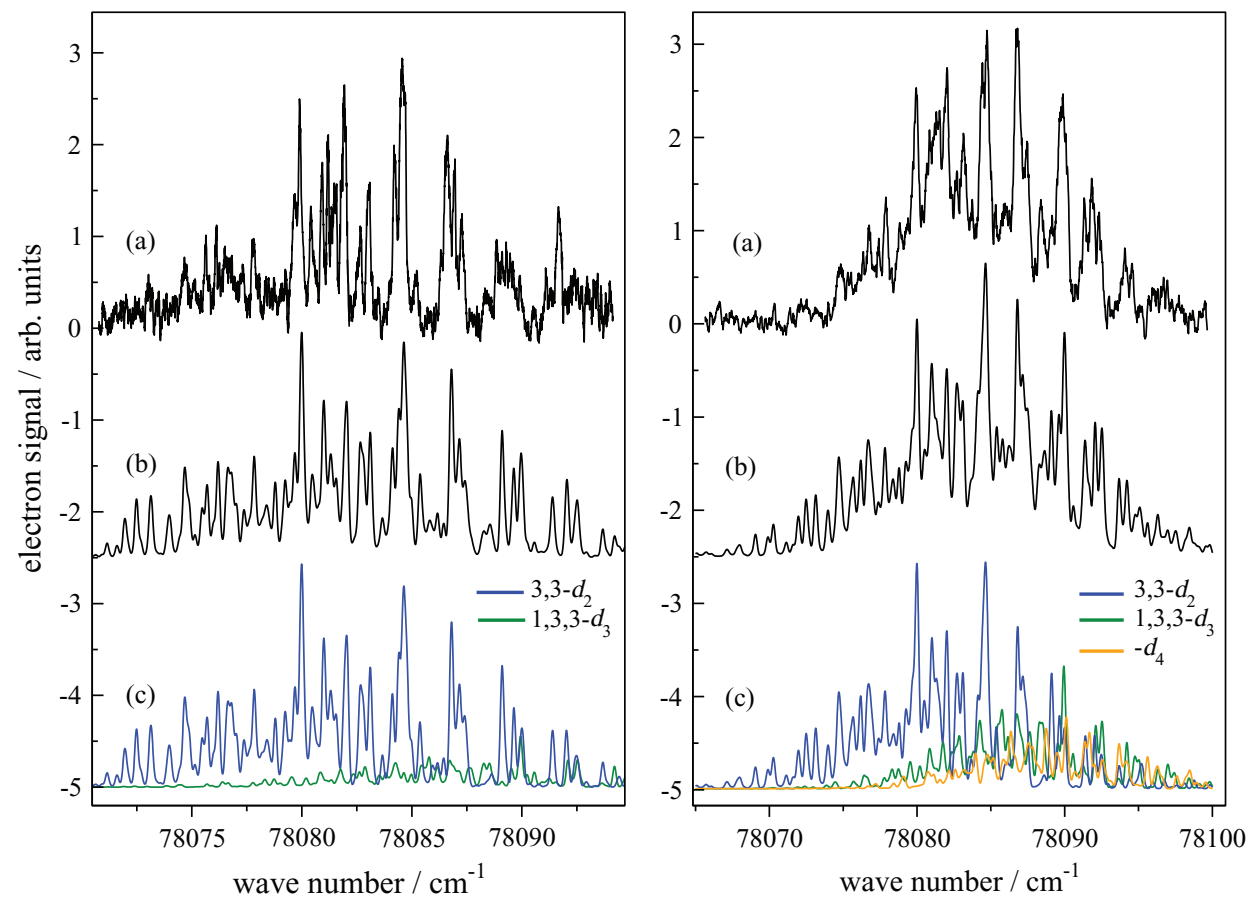

FIG. 9. High-resolution PFI-ZEKE photoelectron spectrum of the origin band of the $\widetilde{\mathrm{X}}^{+} \leftarrow \widetilde{\mathrm{X}}$ ionizing transition of two deuterated samples of cyclopropene. Right and left panels: Results obtained for Samples $2\left(c-\mathrm{CD}_{2}(\mathrm{CH})_{2}(53 \%), c-\mathrm{CD}_{2} \mathrm{CDCH}(35 \%)\right.$, and $\left.c-\mathrm{C}_{3} \mathrm{D}_{4}(8 \%)\right)$ and $3\left(c-\mathrm{CHD}(\mathrm{CH})_{2}(15 \%), c-\mathrm{CD}{ }_{2}(\mathrm{CH})_{2}\right.$ (77\%), and $c-\mathrm{CD}_{2} \mathrm{CDCH}(6 \%)$ ), respectively. Traces (a): Experimental spectra. Traces (b): Calculated spectra obtained by convolution of stick spectra (not shown) with a Gaussian function of full width at half maximum of $0.25 \mathrm{~cm}^{-1}$. Traces (c): Decomposition of the spectra into the contributions of $c-\mathrm{CD}_{2}(\mathrm{CH})_{2}$ (blue line), $c-\mathrm{CD}_{2} \mathrm{CDCH}$ (green line), and $c-\mathrm{C}_{3} \mathrm{D}_{4}$ (orange line). 
of $-831 \mathrm{mV} / \mathrm{cm}$ had to be applied to achieve a sufficiently high signal-to-noise ratio. From the spectrum (not shown) the value of the adiabatic ionization energy of $c-\mathrm{CHD}(\mathrm{CH})_{2}$ was determined to be $78008.3(20) \mathrm{cm}^{-1}$.

\section{Photoionization mass spectrometry and spectroscopy}

The different isotopomers present in the deuterated samples pose a problem in the identification of specific bands of the survey photoelectron spectra to a given isotopomer. To overcome this problem, the photoelectron spectra were complemented by photoionization spectra. In photoionization spectroscopy, the yield of ions of a certain mass is recorded as a function of the wave number of the ionizing radiation. Each time an ionization threshold is crossed, an ionization channel opens and the ion signal is expected, ideally, to rise in a stepwise manner. However, interactions between different ionization channels, which lead to autoionization resonances in photoionization spectra, can make the steps difficult to observe. ${ }^{23}$ In cases where the Rydberg states are predissociative, however, the contributions of autoionizing resonances to photoionization spectra can be strongly suppressed. ${ }^{23}$ The combination of mass-selective photoionization spectroscopy with photoelectron spectroscopy, which is not mass selective, then represents a powerful tool for the spectroscopic investigation of samples that are mixtures of several species.

In the upper panel of Fig. 10, traces (b), (c), and (d) correspond to the photoionization spectra of $c-\mathrm{CD}_{2}(\mathrm{CH})_{2}$, $c-\mathrm{CD}_{2} \mathrm{CDCH}$, and $c-\mathrm{C}_{3} \mathrm{D}_{4}$, respectively, obtained with Sample 2 (see Table I). The intensity scale was corrected for the variation of the intensity of the VUV radiation, and the relative intensities of the different spectra reflect the relative abundances of the corresponding isotopomers. The photoionization spectra of $c-\mathrm{C}_{3} \mathrm{H}_{4}$ and $c-\mathrm{CHD}(\mathrm{CH})_{2}$ are not shown, because the signal-to-noise ratio was insufficient to extract useful information. For comparison, the PFI-ZEKE photoelectron spectrum of this sample recorded over the same wave-number range is displayed as Trace (a) in Fig. 10. In all three photoionization spectra, the signal rises sharply from a background level of nearly zero, forming a step near 78083 $\mathrm{cm}^{-1}$ at the position of the first adiabatic ionization energy. Additional steps are visible in the photoionization spectra, the first one located at approximately $78255 \mathrm{~cm}^{-1}$ and common to all three isotopomers, and the others at around 78340 $\mathrm{cm}^{-1}$ (Trace (d)), $78360 \mathrm{~cm}^{-1}$ (Trace (c)), and $78380 \mathrm{~cm}^{-1}$ (Trace (b)) for $c-\mathrm{C}_{3} \mathrm{D}_{4}^{+}, c-\mathrm{CD}_{2} \mathrm{CDCH}^{+}$, and $c-\mathrm{CD}_{2}(\mathrm{CH})_{2}^{+}$, respectively. Every stepwise increase in the photoionization signal corresponds to a line in the photoelectron spectrum and vice versa, as highlighted by the dashed vertical lines that connect the lines of the PFI-ZEKE spectrum with the steps observed in the photoionization spectra. The photoionization spectra therefore exhibit an almost ideal behavior in this wave-number range, which allows the decomposition of the PFI-ZEKE photoelectron spectrum of the mixture into contributions from selected isotopomers and the reconstruction of the vibrational energy-level structure of the corresponding cations. The absence of autoionization resonances in the photoionization spectrum of cyclopropene further indicates that

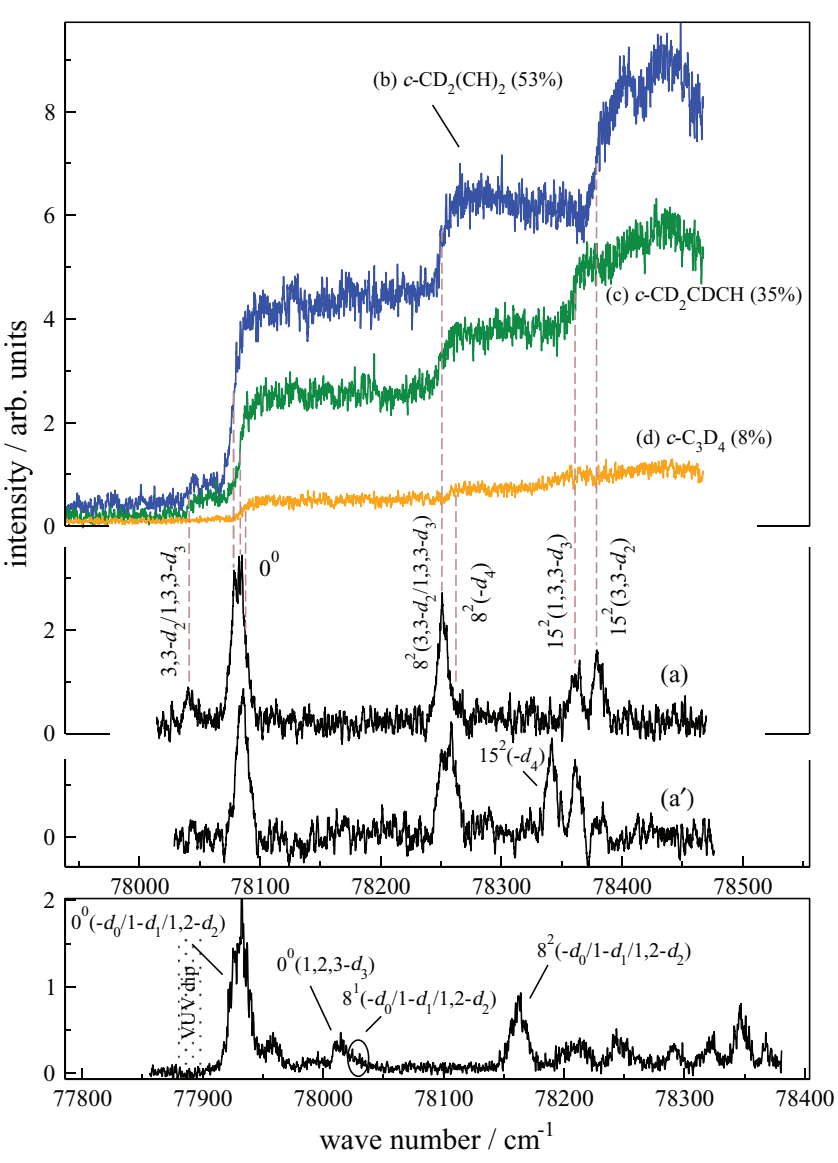

FIG. 10. Upper panel, Traces (a) and ( $\left.\mathrm{a}^{\prime}\right)$ : PFI-ZEKE photoelectron spectrum of the $\widetilde{\mathrm{X}}^{+} \leftarrow \widetilde{\mathrm{X}}$ photoionizing transition of $c-\mathrm{CD}_{2}(\mathrm{CH})_{2}, c-\mathrm{CD}_{2} \mathrm{CDCH}$, and $c-\mathrm{C}_{3} \mathrm{D}_{4}$ recorded with the deuterated Samples 2 and 1, respectively (see Table I for their compositions). Upper panel, Traces (b), (c), and (d): Photoionization spectra of $c-\mathrm{CD}_{2}(\mathrm{CH})_{2}, c-\mathrm{CD}_{2} \mathrm{CDCH}$, and $c-\mathrm{C}_{3} \mathrm{D}_{4}$, respectively, obtained from Sample 2. The vertical dashed lines connect the steps in the photoionization spectra with the peaks of the corresponding PFI-ZEKE photoelectron spectrum (Trace (a)). Lower panel: PFI-ZEKE photoelectron spectrum of the $\widetilde{\mathrm{X}}^{+} \leftarrow \widetilde{\mathrm{X}}$ photoionizing transition of $c-\mathrm{C}_{3} \mathrm{H}_{4}, c-\mathrm{CH}_{2}(\mathrm{CH})(\mathrm{CD})$, $c-\mathrm{CH}_{2}(\mathrm{CD})_{2}$, and $c$ - $\mathrm{CHD}(\mathrm{CD})_{2}$ recorded with Sample 4 (see Table I for its composition).

the Rydberg states of cyclopropene are subject to rapid predissociation in the region of the adiabatic ionization threshold.

The PFI-ZEKE photoelectron spectra obtained using Samples 1 and 4 (see Table I for their compositions) are displayed in Traces $\left(a^{\prime}\right)$, and in the bottom panel of Fig. 10, respectively. The lines observed in these spectra can be assigned to specific isotopomers by comparison with the corresponding photoionization spectra (not shown) using the same procedure. For the identification, we use a short notation in which the numbers separated by a comma indicate the carbon atoms to which the deuterium atoms are attached and the suffix " $-d_{i}$ " with $i=0-4$ gives the number of deuterium atoms. The analysis confirms the adiabatic ionization energies determined from the decomposition of the highresolution photoelectron spectra presented in Sec. IV B. Their values are primarily determined by the degree of deuteration of the methylenic group: The adiabatic ionization energies of $c-\mathrm{C}_{3} \mathrm{H}_{4}, c-\mathrm{CH}_{2} \mathrm{CHCD}, c-\mathrm{CH}_{2}(\mathrm{CD})_{2}$ are located around $77930 \mathrm{~cm}^{-1}$, those of $c-\mathrm{CHD}(\mathrm{CH})_{2}$ and $c-\mathrm{CHD}(\mathrm{CD})_{2}$ around 
$78010 \mathrm{~cm}^{-1}$, and those of $c-\mathrm{CD}_{2}(\mathrm{CH})_{2}, c-\mathrm{CD}_{2} \mathrm{CDCH}$, and $c-\mathrm{C}_{3} \mathrm{D}_{4}$ around $78085 \mathrm{~cm}^{-1}$ (see Tables III and IV).

Below the adiabatic ionization thresholds, the photoionization spectra of $c-\mathrm{CD}_{2}(\mathrm{CH})_{2}, c-\mathrm{CD}_{2} \mathrm{CDCH}$ and $c-\mathrm{C}_{3} \mathrm{D}_{4}$ reveal a weak step at $\sim 78045 \mathrm{~cm}^{-1}$ at the same position as a weak line in the PFI-ZEKE photoelectron spectrum of sample 2 (Trace (a)). These weak features must correspond to a sequence band. The fundamental wave numbers of the lowestfrequency vibration in the neutral species, the $\mathrm{CH}$ (or $\mathrm{CD}$ ) out-of-plane bend $\left(v_{15}^{+}\right)$, amounts to $562 \mathrm{~cm}^{-1}, 471 \mathrm{~cm}^{-1}$, and $424 \mathrm{~cm}^{-1}$ for the doubly, triply, and the fully deuterated cyclopropene isotopomers, respectively. ${ }^{17}$ These sequence bands may therefore correspond to transitions from the fundamental out-of-plane bending levels of the neutral species to the fundamental out-of-plane bending levels of the radical cations $\left(14^{1}\right.$ for $c-\mathrm{CD}_{2}(\mathrm{CH})_{2}^{+}$and $c-\mathrm{C}_{3} \mathrm{D}_{4}^{+}$and $13^{1}$ for $c-\mathrm{CD}_{2} \mathrm{CDCH}^{+}$, see Table II). From this very tentative assignment, one would deduce out-of-plane bending fundamental wave numbers of $\approx 525 \mathrm{~cm}^{-1}\left(14^{1}\right)$ for $c-\mathrm{CD}_{2}(\mathrm{CH})_{2}^{+}, \approx 430 \mathrm{~cm}^{-1}\left(13^{1}\right)$ for $c$ $\mathrm{CD}_{2} \mathrm{CDCH}^{+}$, and $\approx 385 \mathrm{~cm}^{-1}\left(14^{1}\right)$ for $c-\mathrm{C}_{3} \mathrm{D}_{4}^{+}$.

The PFI-ZEKE photoelectron spectrum of the fourth sample displayed in the lower panel of Fig. 10 is more congested than the photoelectron spectra presented as traces (a) and $\left(a^{\prime}\right)$ because the sample contains isotopomers with different degrees of deuteration of the methylenic group which have different origins, at about $77930 \mathrm{~cm}^{-1}$ for the isotopomers containing an undeuterated methylenic group and at about $78010 \mathrm{~cm}^{-1}$ for the isotopomers containing a singly deuterated methylenic group. Above $78200 \mathrm{~cm}^{-1}$, the spectral density is too high for unambiguous assignments to be made.

The positions of the ionization thresholds of the various deuterated isotopomers of cyclopropene determined from photoelectron and photoionization spectra are listed in Table III. The observed isotopic shifts served as a basis for the spectral assignments presented in Subsection IV D.

\section{Assignment of the vibrational structure of $c-\mathrm{C}_{3} \mathrm{H}_{4}^{+}$, $c-\mathrm{CH}_{2} \mathrm{CHCD}^{+}, c-\mathrm{CH}_{2}(\mathrm{CD})_{2}^{+}, c-\mathrm{CD}_{2}(\mathrm{CH})_{2}^{+}, c-\mathrm{CHD}(\mathrm{CD})_{2}^{+}$, $c-\mathrm{CD}_{2} \mathrm{CDCH}^{+}$, and $c-\mathrm{C}_{3} \mathrm{D}_{4}^{+}$at low energies}

The photoelectron spectra of $c$ - $\mathrm{C}_{3} \mathrm{H}_{4}^{+}$(see Fig. 6) and deuterated isotopomers (see Fig. 10) consist of three dominant features at low energies, the first one corresponding to the adiabatic ionization energies, and the other two to two low-lying vibrational levels of the cations. These levels behave differently upon deuteration. The vibrational wave number of the first level $\left(230(2) \mathrm{cm}^{-1}\right.$ in $c-\mathrm{C}_{3} \mathrm{H}_{4}^{+}$) is insensitive to deuteration at the ethylenic sites but shifts by about $-30 \mathrm{~cm}^{-1}$ upon each successive deuteration at the methylenic site, which indicates that the vibrational motion is localized at the methylenic group. The vibrational wave number of the second level $\left(414(2) \mathrm{cm}^{-1}\right.$ in $\left.c-\mathrm{C}_{3} \mathrm{H}_{4}^{+}\right)$is reduced by $\approx 110 \mathrm{~cm}^{-1}$ upon double deuteration at the methylenic site and by $\approx 20 \mathrm{~cm}^{-1}$ upon each deuteration at the ethylene sites. This behavior is indicative of a complex vibrational motion of the cation involving primarily the $\mathrm{CH}_{2}$ group and, to a lesser extent, also the ethylenic hydrogen atoms.
We conclude from the observed isotopic shifts that the two main bands associated with excited vibrational levels of the cyclopropene radical cation must correspond to two different low-frequency vibrational modes. According to $a b$ initio calculations, the two lowest vibrational modes of $c-\mathrm{C}_{3} \mathrm{H}_{4}^{+}$ are the $\mathrm{CH}_{2}$ torsional mode and a mode corresponding to a combination of $\mathrm{CH}_{2}$-rocking and $\mathrm{CH}$-out-of-plane-bending motion. ${ }^{22}$ Because neither of these modes is totally symmetric in the $C_{2 \mathrm{v}}(\mathrm{M})$ group, one would only expect to observe transitions to levels with an even number of vibrational quanta. Moreover, the analysis of the rotationally resolved photoelectron spectra presented in Subsection IV B indicated that these vibrational levels of the cation are totally symmetric $\left(\mathrm{A}_{1}\right)$, from which one must conclude that they are overtones: overtone of the $\mathrm{CH}_{2}$ torsion (i.e., $8^{2}$ ) for the level of $c-\mathrm{C}_{3} \mathrm{H}_{4}^{+}$ observed $230(2) \mathrm{cm}^{-1}$ above the origin, and overtone of the combined $\mathrm{CH}_{2}$-rocking and the $\mathrm{CH}$-out-of-plane motion (i.e., $15^{2}$ ) for the level observed $414(2) \mathrm{cm}^{-1}$ above the origin. This interpretation further enables the assignments of (1) the very weak band at $78043 \mathrm{~cm}^{-1}$ in the photoelectron spectrum of $c-\mathrm{C}_{3} \mathrm{H}_{4}$ (see Fig. 6) to a nominally "forbidden" transition to the fundamental of the $\mathrm{CH}_{2}$ torsional mode, $8_{0}^{1}$, (2) the band at $78503 \mathrm{~cm}^{-1}$ to the $8_{0}^{4}$ transition, and (3) part of the broader structure observed at $\approx 78820 \mathrm{~cm}^{-1}$ to the $15_{0}^{4}$ transition. All vibrational assignments are summarized in Table III.

The fundamental wave numbers obtained from our photoelectron spectra are compared to those calculated $a b$ initio $^{22}$ for the $C_{2}$ equilibrium structure and the $C_{2 \mathrm{v}}$ saddle point in Table V. Comparing our results with the results of these $a b$ initio calculations leads to three main observations: (i) Whereas our results indicate a $C_{2 \mathrm{v}}\left(R_{0}\right)$ structure for the $\widetilde{\mathrm{X}}^{+}$ state of $c-\mathrm{C}_{3} \mathrm{H}_{4}^{+}$, the calculations predict two equivalent $C_{2}$ equilibrium structure $\left(R_{\mathrm{e}}\right)$ separated by a potential barrier of $490 \mathrm{~cm}^{-1}$ along the torsional coordinate, with maximum (saddle point) at the $C_{2 \mathrm{v}}$ structure. The height of the potential barrier is predicted to rise to $690 \mathrm{~cm}^{-1}$ upon inclusion of zeropoint-energy corrections. (ii) The fundamental wave number we determined for the $\mathrm{CH}_{2}$-torsional mode $\left(v_{8}\right)$ is significantly smaller than that determined $a b$ initio for the $C_{2}$ structure, which is a direct consequence of (i). (iii) The fundamental wave number we determined for the $\mathrm{CH}_{2}$-rocking mode $\left(v_{15}\right)$ is significantly smaller than that determined ab initio for the $C_{2 \mathrm{v}}$ saddle point, but similar to that calculated for the $C_{2}$ equilibrium structure.

Our spectroscopic observations indicate a pronounced anharmonicity of the low-frequency vibrational modes, which may be the reason for these discrepancies. The calculations

TABLE V. Comparison of the experimental and the ab initio calculated vibrational wave numbers of the $\mathrm{CH}_{2}$ torsional and $\mathrm{CH}_{2}$ rocking modes.

\begin{tabular}{lccc}
\hline \hline Character & $\begin{array}{c}\text { Vibr. wave } \\
\text { numbers (exp) }\end{array}$ & $\begin{array}{c}\text { CCSD(T)/cc-pVTZ } \\
\left(C_{2} \text { sym. }\right)^{22}\end{array}$ & $\begin{array}{c}\text { MP2/cc-pVQZ } \\
\left(C_{2 \mathrm{v}} \text { sym. }\right)^{22}\end{array}$ \\
\hline $\mathrm{CH}_{2}$ torsion $\left(v_{8}^{+}\right)$ & $111 \mathrm{~cm}^{-1}\left(\mathrm{~A}_{2}\right)$ & $452 \mathrm{~cm}^{-1}(\mathrm{~A})$ & $i 260 \mathrm{~cm}^{-1}\left(\mathrm{~A}_{2}\right)$ \\
$\mathrm{CH}_{2}$ rocking $\left(v_{15}^{+}\right)$ & $\sim 207 \mathrm{~cm}^{-1 \mathrm{a}}\left(\mathrm{B}_{2}\right)$ & $287 \mathrm{~cm}^{-1 \mathrm{~b}}(\mathrm{~B})$ & $541 \mathrm{~cm}^{-1}\left(\mathrm{~B}_{2}\right)$ \\
\hline \hline
\end{tabular}

${ }^{\mathrm{a}}$ Estimated as half the overtone wave number.

${ }^{b}$ The corresponding vibrational motion is delocalized over the whole molecule and the description as " $\mathrm{CH}_{2}$-rocking" is simplified. 
might indeed have overestimated the zero-point-energy corrections. The potential energy along the $\mathrm{CH}_{2}$ torsional mode appears to be flat near the $C_{2 \mathrm{v}}$ structure so that the torsional wave function extends over a wide range of torsional angles, beyond the angle corresponding to the $a b$ initio $C_{2}$ equilibrium structure. We therefore expect the $\mathrm{CH}_{2}$-rocking wave number calculated $a b$ initio for the $C_{2}$ structure to correspond more closely to our experimental result than that calculated for the $C_{2 \mathrm{v}}$ saddle point, in agreement with the data presented in Table V.

\section{CONCLUSIONS}

The rovibrational energy level structures of the cyclopropene radical cation and several deuterated isotopomers have been determined from high-resolution photoelectron and photoionization spectra of the parent neutral molecules in the vicinity of the $\widetilde{\mathrm{X}}^{+} \leftarrow \widetilde{\mathrm{X}}$ photoionizing transition. The rotational structure of the photoelectron bands indicated that the cation has a $C_{2 \mathrm{v}}\left(R_{0}\right)$ structure and enabled the derivation of the vibrational symmetry of several low-lying vibrational levels of $c-\mathrm{C}_{3} \mathrm{H}_{4}^{+}$. The adiabatic ionization energies of $c-\mathrm{C}_{3} \mathrm{H}_{4}$, $c-\mathrm{CHD}(\mathrm{CH})_{2}, c-\mathrm{CH}_{2} \mathrm{CHCD}, c-\mathrm{CH}_{2}(\mathrm{CD})_{2}, c-\mathrm{CD}_{2}(\mathrm{CH})_{2}, c-$ $\mathrm{CHD}(\mathrm{CD})_{2}, c-\mathrm{CD}_{2} \mathrm{CDCH}$, and $c-\mathrm{C}_{3} \mathrm{D}_{4}$ were determined and so were the rotational constants of the ground state of most of the corresponding radical cations.

The vibrational structure of the photoelectron spectra associated with the $\widetilde{\mathrm{X}}^{+} \leftarrow \widetilde{\mathrm{X}}$ transition of cyclopropene was assigned by analyzing the isotopic shifts upon deuteration. Two low-frequency vibrational modes of the cyclopropene radical cation were identified, one associated with the $\mathrm{CH}_{2}$ torsional motion $\left(v_{8}^{+}\right)$, the other with the $\mathrm{CH}_{2}$ rocking motion $\left(v_{15}^{+}\right)$. A vibrational progression exhibiting positive anharmonicity (i.e., characterized by a negative anharmonicity constant) was observed in the $\mathrm{CH}_{2}$ torsional mode $\left(v_{8}^{+}\right)$of $c-\mathrm{C}_{3} \mathrm{H}_{4}^{+}$.

The excitation, from the neutral ground state, of the fundamentals of these modes is forbidden within the FranckCondon approximation. However, the $8_{0}^{1}$ band could be observed as a weak band, presumably because of vibronic interactions. The excitation of the first overtones, $8_{0}^{2}$ and $15_{0}^{2}$, is allowed and, in the case of $c-\mathrm{C}_{3} \mathrm{H}_{4}^{+}$, they are observed at $234 \mathrm{~cm}^{-1}$ and $417 \mathrm{~cm}^{-1}$ above the vibrational ground state, respectively.

The removal of an electron from the highest occupied molecular orbital of cyclopropene, which has a $\mathrm{CC} \pi$ bonding character and $\mathrm{b}_{2}$ symmetry in the $C_{2 \mathrm{v}}$ point group, has a strong impact on the molecular structure, particularly on the $\mathrm{CH}_{2}$ torsional and rocking modes and on the out-of-plane $\mathrm{CH}$ bending modes. The fundamental wave number of the $\mathrm{CH}_{2}$ torsional mode decreases from about $\sim 1000 \mathrm{~cm}^{-1}$ (Ref. 17) in the neutral species to only about $110 \mathrm{~cm}^{-1}$ in the radical cation. Similarly, the fundamental wave number of the $\mathrm{CH}_{2}$ rocking mode decreases from $\sim 1090 \mathrm{~cm}^{-1}$ (Ref. 17) in the neutral species to less than $210 \mathrm{~cm}^{-1}$ in $c-\mathrm{C}_{3} \mathrm{H}_{4}^{+}$. Our spectroscopic observations indicate a pronounced positive anharmonicity of the low-frequency vibrational modes, which may be the reason for the discrepancies with the results of recent high-level ab initio calculations. ${ }^{22}$ One should note, however, that this comparison is complicated by the fact that the observed vibrational structure may be affected by intermode anharmonic couplings and vibronic coupling. The low-frequency modes observed experimentally imply a fluctional behavior of the $\mathrm{H}$ atoms which is related to the delocalization of the $\pi$ bonding orbital over the entire ring. ${ }^{19}$

The occurrence of several low-frequency modes caused significant spectral congestion already at low internal energies of the cation and made the spectra difficult to assign. Systematic deuteration of the different sites, which normally facilitates the assignments did not work as well as we had hoped: All attempts at synthesizing specific deuterated isotopomers resulted in mixtures of several isotopomers. Although the assignment of the dominant spectral structures to individual isotopomers could be made by comparison of the PFI-ZEKE photoelectron spectra with photoionization spectra, several assignments remain uncertain. In future, more selective synthetic routes to produce specific isotopomers, and spectroscopic experiments at higher resolution may help to clarify the discrepancies between our spectroscopic results and the latest $a b$ initio calculations.

\section{ACKNOWLEDGMENTS}

We thank Dr. Urs Hollenstein, Dr. Bérenger Gans, and Dr. René Verel (all three ETH Zurich) for experimental help, and Dr. M. Willeke, Dr. L. Horný (both ETH Zurich), Professor H. F. Schaefer III (University of Georgia, Athens), and Professor J. F. Stanton (University of Texas) for useful discussions. This work is supported financially by the Swiss National Science Foundation under Project No. 200020-146759.

${ }^{1}$ P. Rademacher, Chem. Rev. 103, 933 (2003).

${ }^{2}$ S. D. Peyerimhoff and R. J. Buenker, Theor. Chim. Acta (Berlin) 14, 305 (1969)

${ }^{3}$ E. Kochanski and J. M. Lehn, Theor. Chim. Acta (Berlin) 14, 281 (1969).

${ }^{4}$ J. Kao and L. Radom, J. Am. Chem. Soc. 100, 379 (1978).

${ }^{5}$ J. D. Dunitz, H. G. Feldman, and V. Schomaker, J. Chem. Phys. 20, 1708 (1952)

${ }^{6}$ P. H. Kasai, R. J. Meyers, D. F. Eggers, Jr., and K. B. Wiberg, J. Chem. Phys. 30, 512 (1959).

${ }^{7}$ W. M. Stigliani, V. W. Laurie, and J. C. Li, J. Chem. Phys. 62, 1890 (1975).

${ }^{8}$ N. C. Baird and M. J. S. Dewar, J. Am. Chem. Soc. 89, 3966 (1967).

${ }^{9}$ R. D. Bach and O. Dmitrenko, J. Am. Chem. Soc. 126, 4444 (2004).

${ }^{10}$ P. Thaddeus, S. E. Cummins, and R. A. Linke, ApJ 283, L45 (1984).

${ }^{11}$ M. Bogey, C. Demuynck, J. L. Destombes, and J. C. Guillemin, Chem. Phys. Lett. 125, 569 (1986).

${ }^{12}$ J. M. Vrtilek, C. A. Gottlieb, T. J. LePage, and P. Thaddeus, ApJ 316, 826 (1987).

${ }^{13}$ J. J. Macfarlane, F. S. Shenstone, and J. R. Vickery, Nature (London) 179, 830 (1957).

${ }^{14}$ K. B. Wiberg and B. J. Nist, J. Am. Chem. Soc. 83, 1226 (1961).

${ }^{15}$ D. F. Eggers, Jr., J. W. Schultz, K. B. Wiberg, E. L. Wagner, L. M. Jackman, and R. L. Erskine, J. Chem. Phys. 47, 946 (1967).

${ }^{16}$ R. W. Mitchell, E. A. Dorko, and J. A. Merritt, J. Mol. Spectrosc. 26, 197 (1968).

${ }^{17}$ T. Y. Yum and D. F. Eggers, Jr., J. Phys. Chem. 83, 501 (1979).

${ }^{18}$ K. Kimura, S. Katsumata, Y. Achiba, T. Yamazaki, and S. Iwata, Handbook of HeI Photoelectron Spectra of Fundamental Organic Molecules: Ionization Energies, ab initio Assignments, and Valence Electronic Structure for 200 Molecules (Japan Scientific Societies Press, Tokyo, 1981).

${ }^{19}$ M. B. Robin, C. R. Brundle, N. A. Kuebler, G. B. Ellison, and K. B. Wiberg, J. Chem. Phys. 57, 1758 (1972).

${ }^{20}$ P. Bischof and E. Heilbronner, Helv. Chim. Acta 53, 1677 (1970).

${ }^{21}$ K. B. Wiberg, G. B. Ellison, J. J. Wendoloski, C. R. Brundle, and N. A. Kuebler, J. Am. Chem. Soc. 98, 7179 (1976). 
${ }^{22}$ L. Horný, H. F. Schaefer, F. Ünlü, and M. Willeke, Mol. Phys. 111, 2306 (2013).

${ }^{23}$ F. Merkt, S. Willitsch, and U. Hollenstein, "High-resolution photoelectron spectroscopy," in Handbook of High-Resolution Spectroscopy, edited by M. Quack and F. Merkt (John Wiley and Sons, Chichester, 2011). Vol 3, pp. 1617-1654.

${ }^{24}$ G. L. Closs, L. E. Closs, and W. A. Böll, J. Am. Chem. Soc. 85, 3796 (1963).

${ }^{25}$ R. Signorell and F. Merkt, Mol. Phys. 92, 793 (1997).

${ }^{26} \mathrm{P}$. Binger, P. Wedemann, R. Goddard, and U. H. Brinker, J. Org. Chem. 61, 6462 (1996).

${ }^{27}$ P. Binger, P. Wedemann, and U. H. Brinker, Org. Synth. 77, 254 (2000).

${ }^{28}$ P. Binger, P. Wedemann, and U. H. Brinker, Org. Synth. Coll. Vol. 10, 231 (2004).

${ }^{29}$ H. G. Korth, H. Trill, and R. Sustmann, J. Am. Chem. Soc. 103, 4483 (1981).

${ }^{30}$ I. C. Stewart, B. K. Keitz, K. M. Kuhn, R. M. Thomas, and R. H. Grubbs, J. Am. Chem. Soc. 132, 8534 (2010).

${ }^{31}$ J. Svenda and A. G. Myers, Org. Lett. 11, 2437 (2009).

${ }^{32}$ M. Orfanopoulos, I. Smonou, and C. S. Foote, J. Am. Chem. Soc. 112, 3607 (1990).

${ }^{33}$ M. M. Goerger and B. S. Hudson, J. Org. Chem. 53, 3148 (1988).

${ }^{34}$ E. D. Matveeva, A. S. Erin, D. B. Mitroshin, and A. L. Kurts, Russ. J. Org. Chem. 31, 1121 (1995).
${ }^{35}$ G. Reiser, W. Habenicht, K. Müller-Dethlefs, and E. W. Schlag, Chem. Phys. Lett. 152, 119 (1988)

${ }^{36}$ F. Merkt, A. Osterwalder, R. Seiler, R. Signorell, H. Palm, H. Schmutz, and R. Gunzinger, J. Phys. B 31, 1705 (1998).

${ }^{37}$ U. Hollenstein, H. Palm, and F. Merkt, Rev. Sci. Instrum. 71, 4023 (2000).

${ }^{38}$ U. Hollenstein, R. Seiler, H. Schmutz, M. Andrist, and F. Merkt, J. Chem. Phys. 115, 5461 (2001).

${ }^{39}$ H. C. Longuet-Higgins, Mol. Phys. 6, 445 (1963).

${ }^{40} \mathrm{M}$. Quack, "Fundamental symmetries and symmetry violations from highresolution spectroscopy," in Handbook of High-Resolution Spectroscopy, edited by M. Quack and F. Merkt (John Wiley and Sons, Chichester, 2011). Vol. 1, pp. 659-722.

${ }^{41}$ P. R. Bunker and P. Jensen, Molecular Symmetry and Spectroscopy, 2nd ed. (NRC Research Press, Ottawa, 1998).

${ }^{42}$ R. N. Zare, Angular Momentum (John Wiley and Sons, New York, 1988).

${ }^{43}$ G. Herzberg, Molecular Spectra and Molecular Structure, Volume II, Infrared and Raman Spectra of Polyatomic Molecules (Krieger Publishing Company, Malabar, 1991).

${ }^{44}$ G. Herzberg, Molecular Spectra and Molecular Structure, Volume III, Electronic Spectra and Electronic Structure of Polyatomic Molecules, 2nd ed. (Krieger Publishing Company, Malabar, 1991).

${ }^{45}$ S. Willitsch and F. Merkt, Int. J. Mass Spectrom. 245, 14 (2005).

${ }^{46}$ N. C. Craig and J. Pranata, J. Phys. Chem. 91, 1764 (1987). 